UNIVERSIDADE DE SÃO PAULO

ESCOLA DE ARTES, CIÊNCIAS E HUMANIDADES

PROGRAMA DE PÓS-GRADUAÇÃO EM GERONTOLOGIA

ELIANA DE SOUSA ALVIM SANTOS

Prevalência de prescrições inapropriadas para idosos nas farmácias das unidades da atenção primária

SÃO PAULO

2020 
ELIANA DE SOUSA ALVIM SANTOS

\title{
Prevalência de prescrições inapropriadas para idosos nas farmácias das unidades da
} atenção primária

\author{
Versão Corrigida
}

Dissertação apresentada à Escola de Artes, Ciências e Humanidades da Universidade de São Paulo para obtenção do título de Mestre em Ciências pelo Programa de Pós-Graduação em Gerontologia.

Versão corrigida contendo as alterações solicitadas pela comissão julgadora em 28 de Outubro de 2020 A versão original encontrase em acervo reservado na Biblioteca da EACH/USP e na Biblioteca Digital de Teses e Dissertações da USP (BDTD), de acordo com a Resolução CoPGr 6018, de 13 de outubro de 2011.

Área de Concentração:

Gerontologia

Orientadora:

Profa. Dra. Caroline Ribeiro de Borja Oliveira

São Paulo 
Autorizo a reprodução e divulgação total ou parcial deste trabalho, por qualquer meio convencional ou eletrônico, para fins de estudo e pesquisa, desde que citada a fonte.

Santos, Eliana de Sousa Alvim

Prevalência de prescrições inapropriadas para idosos nas farmácias das unidades da atenção primária / Eliana de Sousa Alvim Santos ; orientadora, Caroline Ribeiro de Borja Oliveira. - 2020 $97 \mathrm{f}$ : il.

Dissertação (Mestrado em Ciências) - Programa de PósGraduação em Gerontologia, Escola de Artes, Ciências e Humanidades, Universidade de São Paulo, São Paulo Versão corrigida

1. Saúde do idoso. 2. Idosos. 3. Atenção primária à saúde. 4. Farmacoterapia. 5. Lista de medicamentos potencialmente inapropriados. I. Oliveira, Caroline Ribeiro de Borja, orient. II. Título 
Nome: SANTOS, Eliana de Sousa Alvim

Título: Prevalência de prescrições inapropriadas para idosos nas farmácias das unidades da atenção primária

Dissertação apresentada à Escola de Artes, Ciências e Humanidades da Universidade de São Paulo para obtenção do título de Mestre em Ciências do Programa de Pós-Graduação e Gerontologia.

Área de Concentração:

Gerontologia

Aprovado em: 28/10 /2020

\section{Banca Examinadora}

Prof. Dr. Thais Bento Lima da Silva

Julgamento:

Prof. Dr. Humberto Miguel Garay Malpartida

Julgamento:

Prof. Dr. Julie Silvia Martins

Julgamento:
Instituição: Faculdade de Gerontologia EACHUSP

Assinatura:

Instituição: Faculdade de Gerontologia EACH. USP

Assinatura:

Instituição: Faculdade de Odontologia da Universidade de São Paulo

Assinatura: 
Ao meu marido Edvaldo Gomes (in memoriam) meu parceiro de caminhada, meu amor e meu melhor amigo, por sempre acreditar que eu podia ir além dos meus sonhos. 


\section{AGRADECIMENTOS}

Agradeço primeiramente, a Deus, que me deu ânimo e coragem para iniciar este trabalho.Pois é Deus que efetua em nós tanto o querer quanto o realizar,segundo sua boa vontade.(Filipenses 2:13)

Ao Prof. Dr. Humberto Miguel Garay Malpartida, por me aceitar, orientar e me motivar por um período durante este processo. Obrigada por ampliar meu olhar nesta pesquisa.

A minha orientadora, Prof. ${ }^{a}$. Dra. Caroline Ribeiro de Borja Oliveira, uma luz que Deus colocou no meu caminho. A ela todo meu carinho, gratidão e admiração por me conduzir em parceria em toda esta jornada.

A APS Santa Marcelina por investir em seus colaboradores e possibilitar meio para realização deste trabalho

As minhas parceiras e amigas do Setor de Pesquisa da APS Santa Marcelina, Julie Silvia Martins, e Michele Quevedo por apoiar a pesquisa do uso de medicamentos em idosos na APS.

Aos meus pais, Elias e Maria do Carmo, por serem tão 'preciosos e tornarem meus dias mais leves com seus abraços.

Aos meus filhos Suelen, Caio e Rafael por serem minha motivação de vida e fonte de esperança todos os dias.

Aos meus amigos Samuel Amano Máximo, Adriana Marega e Julie Silvia Martins.Vocês foram presentes incríveis para minha vida e essenciais para concretização deste trabalho. Muitos momentos se tornaram mais leves e mais fáceis graças ao apoio de vocês.

Aos meus amigos e parceiros do Nucleo Tecnico da APS Santa Marcelina pela motivação continua e amizade.Não há nada melhor que encontrar seus sorrisos todas as manhãs.

A minha querida amiga Rita Rebouças por sua luz e alegria.Obrigada por me dar a oportunidade de "olhar o outro lado" e a leveza necessária para alegrar meus dias. 
“Assim resplandeça a vossa luz diante dos homens, para que vejam as vossas boas obras e glorifiquem a vosso Pai, que está nos céus." (BIBLIA, Mateus, 5.16) 


\section{RESUMO}

SANTOS, Eliana de Sousa Alvim. Prevalência de prescrições inapropriadas para idosos nas farmácias das unidades da atenção primária. 2020. 97p. Dissertação (Mestrado em Ciências) - Escola de Artes, Ciências e Humanidades, Universidade de São Paulo, São Paulo, 2020. Versão Corrigida.

Objetivo: Estimar a prevalência de prescrição de medicamentos potencialmente inapropriados para idosos (MPI) e sua associação com polifarmácia, idade e sexo, entre idosos usuários das unidades da Atenção Primária à Saúde (APS), bem como apontar alternativas farmacológicas integrantes da Relação Municipal de Medicamentos Essenciais de São Paulo (REMUME-SP) 2016. Método: Estudo transversal, descritivo e analítico, de abordagem quantitativa, com coletas realizadas entre 2016 a 2019 em três Unidades de Saúde da Secretaria Municipal de Saúde de São Paulo, utilizando dados de prescrições de idosos com idades $\geq 60$ anos, usuários das farmácias das Unidades de Saúde. O instrumento de identificação de MPI foi o Consenso Brasileiro de MPI (CBMPI). Alternativas terapêuticas aos MPI foram indicadas com base na literatura. Como medidas de associação entre variáveis, utilizou-se a razão de prevalência (RP), seus intervalos de confiança (IC95\%) e o teste quiquadrado de Pearson. Resultados: Participaram da pesquisa 562 usuários, cuja idade variou entre 60 e 90 anos de idade. A maioria ( $n=330 ; 60,3 \%$; IC95\% = 56,1-64,3) possuía entre 60 e 69 anos era do sexo feminino $(n=363$; IC95\% =61,3-69,2) e possuía prescrição de MPI $n=$ 307; 54,6\%; IC95\% = 50,5-58,7. Quase metade dos participantes $(\mathrm{n}=277 ; 49,3 \%$; IC95\% = $45,2-53,4)$ apresentou prescrições de cinco ou mais medicamentos (polifarmácia) (mediana = 4; IIQ = 3-6). O número de MPI prescritos variou entre 1 e 5 (mediana = 1; IIQ = 1-2). Houve associação estatisticamente significativa entre número de medicamentos prescritos e prescrição de MPI (RP = 1,87; IC95\% = 1,59 - 2,20; p < 0,0001). Foram prescritos 30 MPI diferentes e os mais prevalentes foram o inibidor da bomba de prótons (protetor gástrico) omeprazol (utilizado por 181 participantes; 32,2\%; IC95\% = 28,3-36,1), o antidiabético glibenclamida $(\mathrm{n}=59 ; 10,5 \%$; IC95\% $=8,0-13,0)$ e o diurético furosemida $(\mathrm{n}=49 ; 8,7 \%$; IC95\% = 6,4-11,1). Os antiinflamatórios não esteroidais (AINES) foram prescritos para 42 $(7,4 \%$; IC95\% = 5,3-9,6) participantes. Dos 30 diferentes MPI prescritos, 28 (93\%) constavam na REMUME-SP, onde foram encontradas alternativas farmacológicas para 16 $(53,3 \%)$ deles. Conclusão: Os dados demonstraram que a polifarmácia eleva o risco de prescrição de MPI, corroborando achados encontrados na literatura, obtidos em outros contextos. O fato de quase todos os MPI prescritos constarem na REMUME apontam para a 
necessidade de se incluir nos protocolos clínicos da Relação Nacional (RENAME) as restrições para uso desses medicamentos em idosos, constantes no Consenso Brasileiro de MPI. A disponibilidade, na REMUME-SP, de alternativas supostamente mais seguras para mais da metade dos MPI prescritos, observada nesta pesquisa, mostra que não basta disponibilizá-las na REMUME-SP; é necessário promover conscientização sobre a necessidade de prescrevê-las para o idoso no lugar dos MPI sempre que possível, decisão esta que evidentemente deve ser baseada numa avaliação individualizada do usuário e das condições clínicas a serem tratadas.

Palavras-chave: Saúde do Idoso. Farmacoterapia. Medicamentos potencialmente inapropriados. 


\begin{abstract}
SANTOS, Eliana de Sousa Alvim. Prevalence of inappropriate prescriptions for elderly in primary care pharmacies. 2020. 97p. Dissertation (Master of Sciences) -School of Arts, Sciences and Humanities, University of São Paulo, São Paulo, 2020. Correted version.
\end{abstract}

Objective: To estimate the prevalence of prescription of potentially inappropriate medications for the elderly (PIM) and its association with polypharmacy, age and sex, among elderly users of Primary Health Care units, as well as to point out pharmacological alternatives that are part of the Municipal List of Essential Medicines of São Paulo (REMUME-SP) 2016. Method: Cross-sectional, descriptive and analytical study, with a quantitative approach, with collections carried out between 2016 and 2019 in three Primary Health Care units of São Paulo, using data from prescriptions of elderly people aged $\geq 60$ years, users of pharmacies in the Health Units. The instrument for identifying MPI was the Brazilian Consensus on MPI (CBMPI). Therapeutic alternatives to MPI have been indicated based on the literature. As measures of association between variables, the prevalence ratio (PR), its confidence intervals (95\% CI) and Pearson's chi-square test were used. Results: 562 older adults participated in the research, whose age varied between 60 and 90 years. Most of them $(\mathrm{n}=330 ; 60.3 \% ; 95 \% \mathrm{CI}=56.1-64.3)$ were between 60 and 69 years old were female $(\mathrm{n}$ $=363 ; 95 \% \mathrm{CI}=61.3-69.2)$ and had MPI prescription $\mathrm{n}=307 ; 54.6 \% ; 95 \% \mathrm{CI}=50.5-58.7$. Almost half of the participants $(n=277 ; 49.3 \%$; 95\% CI $=45.2-53.4)$ had prescriptions for five or more medications (polypharmacy) (median $=4$; IIQ $=3-6$ ). The number of MPI prescribed varied between 1 and 5 (median $=1$; IIQ $=1-2$ ). There was a statistically significant association between the number of medications prescribed and the MPI prescription $(\mathrm{PR}=1.87 ; 95 \% \mathrm{CI}=1.59-2.20 ; \mathrm{p}<0.0001)$. Thirty different MPI were prescribed and the most prevalent were the proton pump inhibitor (gastric protector) omeprazole (used by 181 participants; 32.2\%; 95\% CI $=28.3-36.1$ ), the antidiabetic glibenclamide $(\mathrm{n}=59 ; 10.5 \% ; 95 \% \mathrm{CI}=8.0-13.0)$ and the diuretic furosemide $(\mathrm{n}=49 ; 8.7 \%$; $95 \% \mathrm{CI}=6.4-11.1)$. Non-steroidal anti-inflammatory medications (NSAIDs) were prescribed for $42(7.4 \%$; 95\% CI = 5.3-9.6) participants. Of the 30 different MPI prescribed, 28 (93\%) were in REMUME-SP, where pharmacological alternatives were found for $16(53,3 \%)$ of them. Conclusion: The data demonstrated that polypharmacy increases the risk of prescribing MPI, corroborating findings found in the literature, obtained in other contexts. The fact that almost all the prescribed PIMs are included in REMUME point to the need to include in the national protocols of the National List (RENAME) the restrictions for the use of these 
medications in the elderly, contained in the Brazilian PIM Consensus. The availability, in REMUME-SP, of supposedly safer alternatives for most of the prescribed MPI, observed in this research, shows that it is not enough to make them available in REMUME-SP; it is necessary to promote awareness of the need to prescribe them for the elderly in place of PIMs whenever possible, a decision that must be based on an individualized assessment of the elderly and the clinical conditions to be treated.

Key words: Elderly health. Pharmacotherapy. Potentially inappropriate medication for elderly people 


\section{LISTA DE TABELAS}

Tabela 1 -Prevalências e IC 95\% das variáveis estudadas em usuários da atenção primária. São Paulo, 2016 - 2019.

Tabela 2 - Associação entre prescrição de MPI e as variáveis estudadas entre usuários das unidades de atenção primária. São Paulo, 2016 - 2019. .36

Tabela 3 - Prevalência de MPI prescritos aos participantes da pesquisa, justificativas para a restrição em idosos e alternativas terapêuticas. São Paulo, 2016 - 2019. 


\section{LISTA DE ABREVIATURAS E SIGLAS}

$\begin{array}{lll}\text { APS } & \text { - } & \text { Atenção Primária a Saúde } \\ \text { CBMPI } & - & \text { Consenso Brasileiro de Medicamentos Potencialmente Inapropriados } \\ \text { para Idosos } & & \\ \text { DCNTs } & - & \begin{array}{l}\text { Doenças Crônicas Não Transmissíveis } \\ \text { IE }\end{array} \\ \text { IBGE } & - & \text { Indice de Envelhecimento } \\ \text { IC } & - & \text { Instituto Brasileiro de Geografia e Estatística } \\ \text { IIQ } & - & \text { Intervalo de Confiança } \\ \text { MPI } & - & \text { Medicamentos Potencialmente Inapropriados para Idosos } \\ \text { OMS } & - & \text { Organização Mundial da Saúde } \\ \text { PNAD } & - & \text { Pesquisa Nacional por Amostra de Domicílios } \\ \text { PNS } & - & \text { Pesquisa Nacional de Saúde } \\ \text { PNAUM } & - & \text { Pesquisa Nacional sobre o Acesso, Utilização e Promoção do Uso }\end{array}$

Racional de Medicamentos

PPI - Prescrição Potencialmente Inapropriada

RAM - Reação Adversa a Medicamentos

REMUME - Relação Municipal de Medicamentos Essenciais

RENAME - Relação Nacional de Medicamentos Essenciais

RIPSA - $\quad$ Rede Integrada de Informações para a Saúde

RP $\quad$ - Razão de Prevalência

SUS $\quad$ - $\quad$ Sistema Único de Saúde

SEADE - - Sistema Estadual de Análise de dados

TCLE - $\quad$ Termo de Consentimento Livre e Esclarecido

WHO - $\quad$ World Health Organization 


\section{SUMÁRIO}

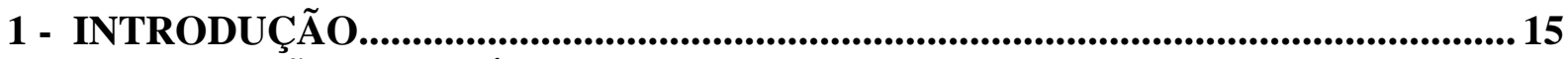

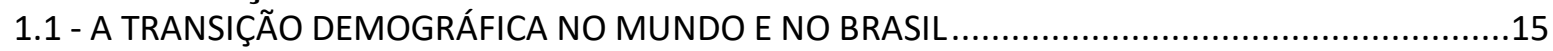

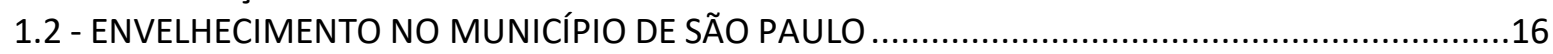

1.2.2 - Distribuição da população idosa na cidade de São Paulo................................................18

1.3 - MUDANÇA DE PERFIL EPIDEMIOLÓGICO DA POPULAÇÃO E IMPACTO NA SAÚDE PÚBLICA ....18

1.4 - ALTERAÇÕES FISIOLÓGICAS NO ENVELHECIMENTO E FARMACOLOGIA NO IDOSO .................19

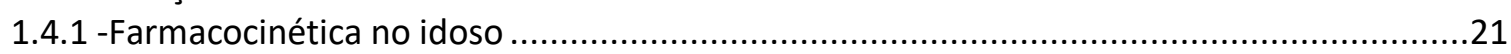

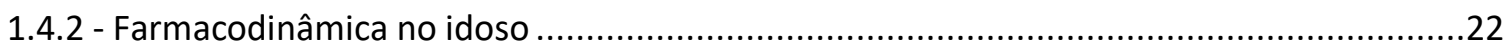

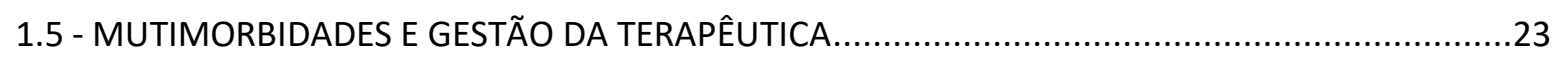

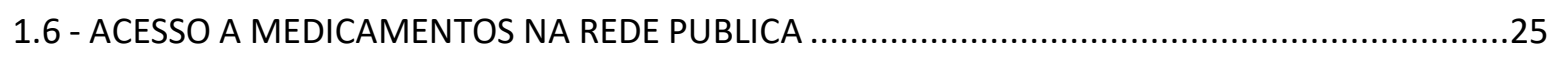

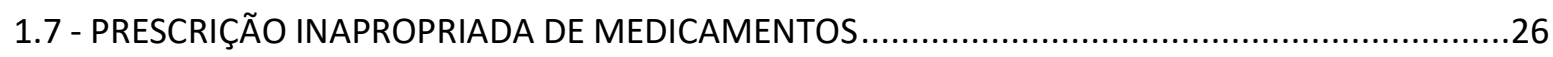

2. JUSTIFICATIVA..................................................................................................................31

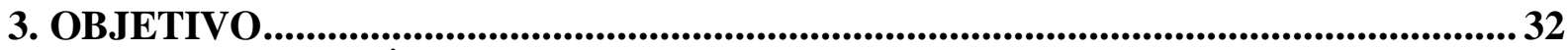

4. MATERIAIS E MÉTODOS ............................................................................33

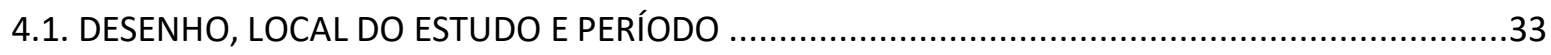

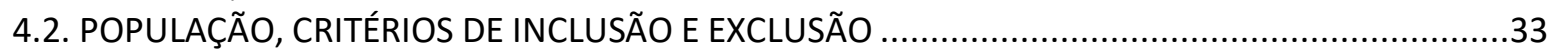

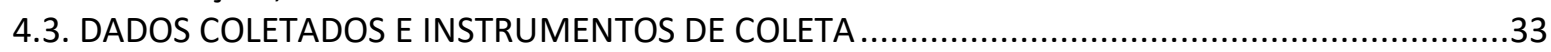

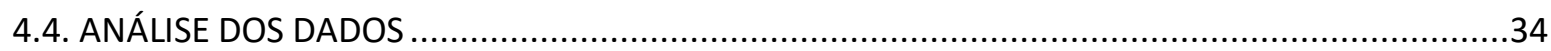

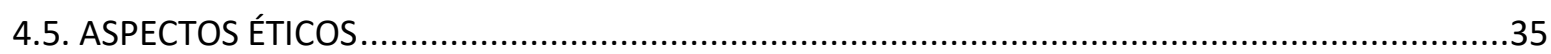

5. RESULTADOS …..............................................................................................................36

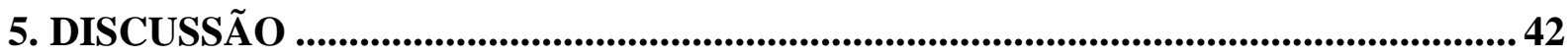

6. CONCLUSÃO E CONSIDERAÇÕES FINAIS ……............................................47

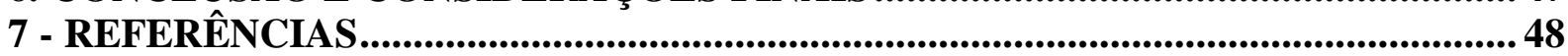

ANEXO 1 - Planilha de prescrição de medicamentos...............................................................54

ANEXO 2 - Quadro 1 do CBMPI. ............................................................................................55

ANEXO 3 - Termo de consentimento livre e esclarecido .....................................................59 


\section{1 - INTRODUÇÃO}

\section{1 - A TRANSIÇÃO DEMOGRÁFICA NO MUNDO E NO BRASIL}

A transição demográfica se inicia com as significativas alterações na estrutura etária da população causadas pela redução das taxas de mortalidade e posteriormente pela queda das taxas de natalidade (MIRANDA; MENDES; SILVA, 2016). A expectativa de vida da população sofreu um acréscimo nas décadas de 40 a 70, devido à evolução das tecnologias de saúde, aos avanços na saúde pública e no saneamento básico, bem como aos processos de urbanização e de planejamento familiar, que colaboraram com a significativa redução da fecundidade, o que resultou em um aumento da proporção de pessoas com 65 anos ou mais (FONSECA; CARMO, 2000; NÓBREGA; KARNIKOWSKI, 2005).

De acordo com o relatório sobre Epidemiologia e Envelhecimento de 1984 da OMS, nos países desenvolvidos, estes indivíduos com 65 anos ou mais são considerados idosos. Já nos países em desenvolvimento, são consideradas idosas as pessoas com idade igual ou superior a 60 anos (WHO, 1984). De fato, a legislação brasileira dispõe no Estatuto do idoso (BRASIL, 2003) e na Política Nacional do Idoso (BRASIL, 2006) que se classifica como idoso o indivíduo pertencente ao grupo com idade igual ou superior a 60 anos.

De qualquer maneira, o envelhecimento da população tem aumentado de forma acelerada em todo mundo, tornando urgente a adaptação das políticas públicas, dos profissionais de saúde e dos sistemas de saúde a esta nova tendência (WHO, 2015). Um país cuja população na faixa de 65 anos é inferior a 7\%, é considerado um país jovem; quando este índice alcança os 14\%, o país passa a ser considerado envelhecido (CHAIMOWICZ, 2013).

Nas nações desenvolvidas, o envelhecimento da população ocorreu de forma lenta, ao longo de mais de cem anos, e alguns países chegaram a apresentar taxas de natalidade mais baixas que as de mortalidade, resultando em um crescimento negativo da sua população. A França, em um período de 115 anos, de 1865 a 1980, evoluiu de um país jovem a um país envelhecido. Este mesmo processo se repetiu na Suécia em um período de 85 anos. É previsto que, em apenas uma geração, países considerados jovens, mas que apresentam uma rápida queda das taxas de fecundidade, tornem-se países envelhecidos (CHAIMOWICZ, 2013).

No Brasil, a população idosa cresce vertiginosamente. Em 1920, a expectativa de vida era de apenas 35 anos e os idosos representavam $4 \%$ da população total do país. Em 2010, essa expectativa dobrou, passando para quase 74 anos. Nessa ocasião, cerca de $11 \%$ 
possuía 60 anos ou mais (BRITO, 2008). Atualmente, a população idosa representa mais de $13 \%$ da população e a expectativa ao nascer já atinge quase 77 anos, ultrapassando, nas mulheres, os 80 anos de idade (IBGE, 2020).

É previsto que o Brasil deixará de ser um país jovem em apenas 25 anos - entre 2011 e 2036 - passando a ser um país envelhecido (CHAIMOWICZ, 2013).

\section{2 - ENVELHECIMENTO NO MUNICÍPIO DE SÃO PAULO}

A aceleração do envelhecimento da população brasileira se destacou na mídia nos últimos anos, devido aos vários debates sobre a reforma da Previdência Social no país. Em função da avaliação realizada pelos últimos Censos Demográficos e por sequenciais contagens populacionais, a projeção do envelhecimento da população em São Paulo encontrase em um estágio mais avançado do que a média nacional (São Paulo, 2019).

Em 2011, a Secretaria de Desenvolvimento Humano através da análise dos dados censitários evidenciou a tendência ao envelhecimento da população paulistana. Os dados censitários demonstraram que as faixas de pessoas idosas passaram de uma parcela de 9,3\% da população em 2000 para 11,9\% em 2010. Os dados censitários de 2011 estimavam que, em pouco mais de uma década, uma em cada cinco pessoas seria idosa (São Paulo, 2011). Segundo a Fundação Seade, em 2018, a população idosa correspondia a 14,7\% da população e as projeções demográficas indicavam que, em 2030, essa representação poderia chegar a $20 \%$ população.

Gráfico 1 - Evolução da população acima de 60 anos, Município de São Paulo 1980 a 2050.

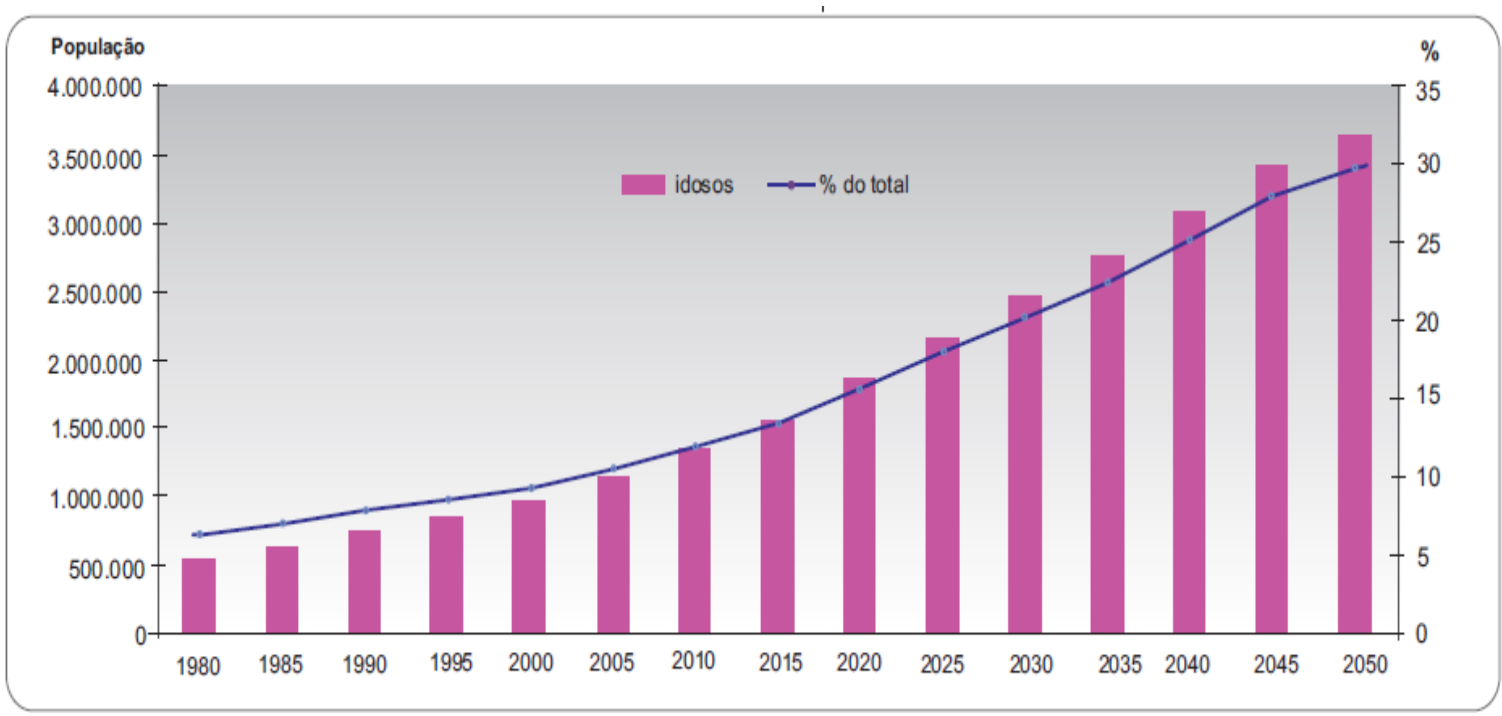

Fonte: Fundação Seade. http://produtos.seade.gov.br/produtos/projpop/index.php Elaboração: SMDU/ Geoinfo 
É possível verificar o nítido processo de envelhecimento em todas as áreas do Município de São Paulo, através de indicadores específicos de projeção. Um indicador sensível para se avaliar este fenômeno é a proporção de idosos na população em um determinado espaço, que indica a proporção relativa de idosos na população geral e reflete seu ritmo de envelhecimento.

Outro indicador importante é o Índice de Envelhecimento (IE), que representa o número de pessoas com mais de 60 anos de idade para cada 100 pessoas menores de 15 anos de idade, na população residente em determinado espaço geográfico, no ano considerado. Para o cálculo deste indicador, frequentemente são utilizadas amostras de idosos entre 65 anos e mais. Entretanto, para atender à política nacional do idoso (Lei no. 8.842, de 4 de janeiro de 1994), utiliza-se aqui o parâmetro de 60 e mais anos (RIPSA, 2012).

O IE, por se tratar de um indicador que relaciona duas faixas etárias opostas, evidencia o processo de transição demográfica. Esse processo é oriundo da redução das taxas de mortalidade e natalidade. (SÃO PAULO,2019). Este indicador permite observar o envelhecimento da população entre áreas geográficas e grupos sociais, podendo subsidiar a formulação, a gestão e a avaliação de políticas públicas na área da saúde (RIPSA, 2012).

\section{Projeção da população por faixas etárias quinquenais, em $1^{\circ}$ de julho}

Região Metropolitana de São Paulo - 2019

IMPRIMIR

\begin{tabular}{lccr}
\hline Faixa Etária - Quinquenal & Homem & Mulher & Total \\
\hline 60 a 64 anos & 438.929 & 544.782 & 983.711 \\
\hline 65 a 69 anos & 327.596 & 426.815 & 754.411 \\
\hline 70 a 74 anos & 219.617 & 309.640 & 529.257 \\
\hline 75 anos e mais & 243.775 & 431.786 & 675.561 \\
\hline Total da Seleção & $\mathbf{1 . 2 2 9 . 9 1 7}$ & $\mathbf{1 . 7 1 3 . 0 2 3}$ & $\mathbf{2 . 9 4 2 . 9 4 0}$ \\
\hline Total Geral da População & $\mathbf{1 0 . 0 9 4 . 8 4 0}$ & $\mathbf{1 0 . 9 0 1 . 9 0 7}$ & $\mathbf{2 0 . 9 9 6 . 7 4 7}$ \\
\hline
\end{tabular}

Fonte: Fundação Seade. http://produtos.seade.gov.br/produtos/projpop/index.php.

Acesso e processamento de dados em 30 nov/ 2019 


\subsection{2 - Distribuição da população idosa na cidade de São Paulo}

A população idosa está desigualmente distribuída no território paulistano, tanto em seu número absoluto, quanto da sua participação relativa na população, proporcionando diagnósticos distintos a partir de cada distrito do municipio. Os distritos com maior população absoluta de idosos localizam-se sobretudo nas porções sul e sudeste do município (SÃO PAULO, 2011).

Embora a população dos distritos periféricos seja mais jovem, a variação do índice de envelhecimento mostra que esta região a que mais envelheceu entre 2010 e 2018. Esta variação positiva nos distritos periféricos está relacionada tanto ao aumento da população idosa, em decorrência das melhorias nas condições gerais de saúde, como também à forte redução da taxa de fecundidade (SÃO PAULO, 2019).

\section{3 - MUdANÇA DE PERFIL EPIDEMIOLÓGICO DA POPULAÇÃO E IMPACTO NA SAÚDE PÚBLICA}

Uma das consequências do crescimento da população idosa e do aumento da esperança de vida ao nascer é a modificação do perfil epidemiológico da população brasileira (MIRANDA; MENDES; SILVA, 2016), no qual a multimorbidade (diagnóstico de duas ou mais doenças crônicas, coexistentes) torna-se cada vez mais frequente, tendo já alcançado mais da metade da população idosa no Brasil (MELO; LIMA, 2018).

A maior longevidade e a prevalência de doenças crônicas não transmissíveis (DCNTs) desencadeiam importantes desafios na área da saúde (CAMPOS; GONÇALVES, 2018). Segundo a Pesquisa Nacional de Amostra de Domicílios (PNAD), em 2008, 31,30\% da população brasileira de todas as faixas etárias referiram ter ao menos um entre os 12 problemas de saúde pesquisados. Observou-se que com o avançar da idade, até 70 anos, a prevalência de pelo menos uma DCNTs apresentrou um aumento significativo e maior ocorrência nas mulheres em todas as faixas etárias (BARROS et al., 2011).

A prevalência das DCNTs alterou o perfil de saúde da população brasileira, acarretando maior sobrecarga para os sistemas de saúde, em função do maior tempo de utilização desses serviços e tratamentos mais complexos e onerosos, devido às complicações decorrentes destas doenças (CHAIMOWICZ, 2006 e CAMPOS; GONÇALVES, 2018).

Esta alteração no perfil demográfico e epidemiológico causam um impacto significativo para o Sistema Único de Saúde (SUS), uma vez que implica um aumento na 
demanda por serviços de saúde especializados para esta população (CAMPOS; GONÇALVES, 2018)

Segundo comparações de estudo das edições PNAD com a Pesquisa Nacional de Saúde (PNS) é possível observar um aumento no acesso e no uso de serviços de saúde no país. De acordo com os indicadores do PNS 2013, o grupo da faixa de 60 anos ou mais tem maior número de consultas médicas durante o ano $(83,5 \%)$, sendo este acesso maior na região Sudeste $(75,8 \%)$. Com relação ao atendimento que inclui prescrição de medicamentos, uma maior proporção de pessoas que conseguiram obter todos os medicamentos receitados foi observada na região Sul $(84,8 \%)$, e a menor na região Norte $(75,8 \%)$. Foi encontrado alto acesso a medicamentos por meio do SUS ou do setor privado de pelo menos um dos medicamentos receitados no último atendimento de saúde (STOPA et al., 2017).

Esse aumento do uso de medicamentos tem um importante impacto econômico na saúde pública não apenas pelo custo associado ao seu provimento, mas também pelos riscos que oferecem, sobretudo nos idosos, em função das alterações fisiológicas do envelhecimento. Estas últimas tornam os indivíduos mais vulneráveis aos seus efeitos indesejáveis.

\section{4 - ALTERAÇÕES FISIOLÓGICAS NO ENVELHECIMENTO E FARMACOLOGIA NO IDOSO}

A Organização Panamericana de Saúde (OPAS, 2005) considera o envelhecer como:

\footnotetext{
"Um processo sequencial, individual, cumulativo, irreversível, universal, não patológico de deterioração de um organismo maduro, próprio a todos os membros de uma espécie, de maneira que o tempo o torne menos capaz de fazer frente ao estresse do meio ambiente e, portanto, aumente sua possibilidade de morte."

O envelhecimento é definido como um processo natural e fisiológico no qual
} ocorre mudanças funcionais, morfológicas, bioquímicas e psicológicas no decorrer da vida. Estas mudanças fisiológicas no envelhecimento ocasionam redução da capacidade de adaptação do indivíduo ao meio ambiente associado a uma maior vulnerabilidade. Como parte integrante do processo de envelhecimento, a velhice é considerada um estado biológico em que o indivíduo se encontra em uma fase da vida (BACHA; PEREZ; VIANNA, 2006).

A partir deste contexto é necessário distinguir senescência e senilidade. A senescência compreende o progressivo declínio de reserva funcional fisiológica que, em condições normais, não acarreta maiores problemas, mas, em situações de estresse, pode levar 
a um estado de desequilíbrio e de incapacidade de readaptação, ocasionando uma descompensação progressiva. Esta pode ser manifestada por diferentes agravos ou doenças. De outro lado, a senilidade é decorrente da somatória de exposição a doenças, trazendo consequências negativas no idoso em função das condições patológicas associadas (CIOSAK, 2011).

A definição de saúde como "um estado de completo bem-estar físico, mental e social e não somente ausência de afecções e enfermidades" (WHO, 1986), não é aplicável quando abordamos o tema saúde do idoso. O conceito de saúde nesta faixa da etária está estritamente relacionado com a sua funcionalidade global e sua capacidade de agir de forma independente e autônoma, mesmo na presença de mutimorbidades (MORAES, 2012).

Esta funcionalidade global depende da preservação dos domínios funcionais, como a cognição (capacidade de resolver problemas), o humor (motivação), a mobilidade (locomoção) e a comunicação (capacidade de se relacionar através dos sentidos visão, fala e audição) que se reflete diretamente na saúde do idoso e em sua qualidade de vida (MORAES; MARINO; SANTOS, 2010).

Em consequência de alterações de qualquer um desses domínios funcionais surgem as síndromes geriátricas que são definidas como sinais e sintomas que resultam na perda da autonomia e da independência (MORAES, 2012). Utiliza-se o termo síndromes geriátricas (GS) para descrever condições comuns em idosos que não são caracterizadas como doenças, mas que podem predispor à incapacidade e morte dos mesmos (INOUYE et al 2007). A incapacidade cognitiva, a instabilidade postural, a imobilidade, a incontinência, incapacidade comunicativa e iatrogenia são consideradas as grandes síndromes geriátricas causadas pelo comprometimento dos principais sistemas funcionais do organismo (MORAES, 2012).

Dentro do contexto da pesquisa, daremos enfoque à iatrogenia, entendida como quaisquer consequências indesejáveis causadas pela prática médica. As iatrogenias estão relacionadas ao uso indevido de medicamentos, à execução inadequada de procedimentos, ou à omissão dos cuidados prestados à saúde. Entre as principais ações iatrogênicas, destaca-se a iatrogenia medicamentosa causada pelo uso excessivo de medicamentos, de polifarmácia, de interações medicamentosas e de prescrições inapropriadas. As prescrições inapropriadas por parte dos profissionais decorrem do desconhecimento das peculiaridades da fisiologia do idoso em relação às alterações farmacocinéticas e farmacodinâmicas que ocorrem na senescência. A iatrogenia é a quinta causa de morte nos Estados Unidos (MORAES; MARINO; SANTOS, 2010 e MATOS, et al., 2017). 
O profissional prescritor deve se atentar ao fato de que as mudanças nas funções fisiológicas corporais resultantes da senescência acarretam uma farmacocinética diferenciada assim como uma maior sensibilidade nos efeitos terapêuticos como também possíveis surgimentos de reações adversas das drogas. Também devem ser considerados uma série de fatores específicos do paciente, incluindo idade, sexo, etnia, genética, processos de doença, polifarmácia, dose e frequência da droga, fatores sociais, e muitos outros fatores que afetam diretamente a farmacocinética, a farmacodinâmica e os resultados clínicos (ALOMAR, 2014).

O idoso apresenta maior sensibilidade a vários medicamentos, devido a queda dos mecanismos homeostáticos que modificam várias funções orgânicas associadas como a redução do fluxo sanguíneo cerebral, hipotensão ortostática, disfunções renal e intestinal, alteração da responsividade do reflexo barorreceptor, dificuldade de termo regulação, queda da capacidade cognitiva, alterações metabólicas e resposta imunitária diminuída (SILVA; SCHMIDT; SILVA, 2012). Estas alterações nas funções orgânicas impactam na resposta farmacológica do idoso resultando em uma significativa variabilidade individual na resposta aos fármacos.

Segundo SCHMIEDEBERG (2010 apud BITTENCOURT; CAPONI; MALUF, 2013), a farmacologia é uma ciência que estuda "os efeitos das substâncias químicas sob condições fisiológicas, que se ocupa da ação dos medicamentos independente de sua importância prática". A farmacologia aborda dois processos que envolvem o medicamento no organismo: a Farmacocinética e a Farmacodinâmica.

A farmacocinética e a farmacodinâmica de um medicamento sofrem modificações em suas etapas no decorrer do processo do envelhecimento, devido a modificações fisiológicas no organismo do idoso, predispondo à ocorrência de Reações Adversas a Medicamentos (RAM), cascata iatrogênica e outras complicações (OLIVEIRA; CORRADI, 2018; GORZONI; FABBRI; PIRES, 2008; PASSARELLI, 2006).

\subsection{1 -Farmacocinética no idoso}

Define-se farmacocinética a relação entre o fármaco e o organismo nos processos absorção, distribuição, metabolismo e excreção da droga. Na velhice, os efeitos de alguns fármacos são diferenciados, devido a alterações da farmacocinética causadas por modificações da absorção, volume de distribuição, permeabilidade da barreira hematoencefálica e de função renal (GORZONI; FABBRI; PIRES, 2008; PASSARELLI, 2006 e CHAIMOWICZ, 2013). 
Uma das alterações fisiológicas no processo natural do envelhecimento ocorre na composição corporal, onde há um menor volume total de água corpórea e maior quantidade de tecido adiposo. Estas alterações corporais impactam diretamente na distribuição dos medicamentos no organismo, sendo que as drogas hidrossolúveis possuem menor biodisponibilidade devido à redução de volume de água corpórea, e as drogas lipossolúveis maior biodisponibilidade devido a maior quantidade de tecido adiposo. Dentro destas alterações, também há diminuição da concentração plasmática de albumina, reduzindo as ligações albumina-droga e causando um aumento da fração livre organismo (NÓBREGA e KARNIKOWSKI, 2005). Essa alteração sérica gera problemas de transporte de substâncias, favorecendo ao risco de intoxicação por medicamentos.

A principal alteração farmacocinética de senescência é a redução da taxa de filtração glomerular (MANSO; BIFFI, 2014; VERA, 2017). A taxa de filtração glomerular diminui lentamente no decorrer do processo de envelhecimento, caindo cerca de $50 \%$ aos 75 anos. (CHAIMOWICZ, 2013). Devido à queda da filtração glomerular a capacidade de excreção fica comprometida, levando a um prolongamento do efeito de certos fármacos no organismo.

A metabolização hepática também declina lentamente, mas de forma variável considerando as condições patológicas do idosos e o reflexo do seu estilo de vida, condições de vida, sexo, estado de saúde e faixa etária (CHAIMOWICZ, 2013). Na senescência, o número de hepatócitos e de massa hepática diminui significativamente gerando uma redução fluxo sanguíneo. Com a redução do sistema enzimático do fígado, há diminuição da velocidade de metabolização reduzindo a produção de metabolitos e mantendo a quantidade total dos fármacos em circulação por um período prolongado (MANSO; BIFFI, 2014; VERA, 2017).

\subsection{2 - Farmacodinâmica no idoso}

Segundo Goodman \& Gilman (1990), a farmacodinâmica pode ser definida como os efeitos das drogas ou fármacos no organismo e a relação da concentração do fármaco em seu sítio de ação. A resposta do processo farmacodinâmico é alterada no processo de envelhecimento através de quatro possíveis mecanismos explicativos: alteração do número de receptores; alteração na afinidade dos receptores; alterações ao nível da transdução do sinal (alteração pós-receptor); e enfraquecimento dos mecanismos de homeostasia devido à idade 
(STARNER, 2009). Estas modificações nas interações fármaco-receptor comprometem o efeito final de um fármaco (GORZONI e PASSARELLI et al , 2006).

Estas modificações na farmacodinâmica agem diretamente na intensidade, duração e ação dos fármacos, tornando os idosos particularmente vulneráveis aos efeitos dos mesmos. Desta forma, eleva-se o risco de ocorrerem reações adversas e interações entre fármacos, agravando-se quanto maior for o número de medicamentos administrados, o tempo de utilização e a dose prescrita (MOSCA; CORREIA, 2012).

\section{5 - MUTIMORBIDADES E GESTÃO DA TERAPÊUTICA}

Estudos populacionais demonstram que o aumento da idade é proporcional à prevalência das doenças crônicas, como doenças cardiovasculares, respiratórias, endócrinas e câncer. Estima-se que 85\% dos idosos apresentam no mínimo uma doença crônica e cerca de 10\% apresentam até cinco dessas enfermidades (ALVES; LEITE; MACHADO, 2008).

A multimorbidade no idoso é muito prevalente e eleva a procura por serviços de saúde, onde em geral a gestão desta condição está associada à desorganização e à fragmentação dos cuidados, dificuldades de aplicação dos cuidados centrados na pessoa e barreiras no processo de partilha de decisão. Existe ainda o problema da inaplicabilidade das diretrizes orientadas para doenças específicas (SINNOTT et al., 2013; REIS; CARDOSO, 2015). Afinal, devido aos múltiplos diagnósticos, o crescente número de pacientes com multimorbidade não se adequa às diversas diretrizes clínicas que são focadas no seguimento de uma única doença (GUTHRIE, 2012; HUNT; KREINER; BRODY, 2012; SINNOTT et al., 2013; REIS; CARDOSO, 2015; MORIARTY et al., 2015).

A dislipidemia, hipertensão, diabetes, depressão são as doenças DCNTs mais prevalentes no idoso e geralmente requerem a utilização de vários medicamentos, caracterizando a polifarmácia (ALMEIDA et al., 2017). Segundo GORZONI e PASSARELLI, 2006 “a polifarmácia é definida como a utilização de dois ou mais medicamentos de uso contínuo por períodos acima de 240 dias ao ano", mas algumas variações da literatura consideram a polifarmácia como o uso de cinco ou mais medicamentos (CARVALHO et al., 2012).

Os medicamentos são a principal opção terapêutica para o tratamento problemas de saúde agudos ou crônicos. A cronicidade das doenças se caracteriza pela longa duração e requerem tratamentos medicamentosos de uso contínuo. Às multimorbidades, as agudizações dos quadros crônicos e os quadros infectocontagiosos aumentam as necessidades de uso de 
medicamentos pelos idosos. Sendo assim, os idosos são os maiores consumidores de medicamentos, o que torna prioridade o acesso aos medicamentos, a implantação de estratégias para o aumento da adesão ao tratamento das DCNTs, e o monitoramento de eventos adversos aos medicamentos (CHAIMOWICZ, 2013).

Segundo GURWITZ et al., 2003, estima-se que 40\% dos idosos com 65 anos ou mais usam 5 ou mais medicamentos, e $12 \%$ usam 10 ou mais medicamentos diferentes. O uso concomitante de vários medicamentos pode trazer resultados indesejáveis ao tratamento, como a menor adesão à terapia medicamentosa, comprometimento capacidade funcional e cognitiva do idoso, ocorrência de reações adversas e interações medicamentosas (ALMEIDA et al., 2017).

O padrão elevado do uso de medicamentos por idosos vem sendo demonstrado em diversos estudos pelo Brasil. Em Ribeirão Preto, constatou-se uma média de uso de sete fármacos por paciente, entre idosos atendidos pelo SUS, sendo que houve um intervalo de um a vinte e um fármacos prescritos. $\mathrm{O}$ uso de seis ou mais princípios ativos esteve presente em 60,1\% dos idosos (BALDONI; PEREIRA, 2010). Em Divinópolis, Minas Gerais, entre idosos atendidos em uma Unidade de APS, a média de medicamentos consumidos foi de 4,3 por idoso e a polifarmácia estava presente em $40 \%$ deles (OLIVEIRA; NASCIMENTO; PEREIRA, 2016).

Os vários diagnósticos levam a uma exposição às prescrições e ao uso de medicamentos potencialmente inapropriados (MPI), o que resulta em eventos adversos e hospitalizações. Em outras palavras, este cenário faz com que a polifarmacoterapia se torne comum neste grupo, em que o risco de prescrições de MPI para a idade é elevado. As prescrições potencialmente inapropriadas estão associadas uso de medicamentos em que os riscos superam os benefícios (MORIARTY et al., 2015).

O MPI é um medicamento que deve ser evitado porque apresentam uma relação risco-benefício desvantajosa para o idoso, expondo-o a eventos adversos; possuem benefícios terapêuticos questionáveis nessa faixa etária; dispõe de alternativa(s) terapêutica(s) mais segura(s) e/ou eficaz(es), seja(m) ela(s) farmacológica(s) ou não.

Por apresentarem uma relação risco-benefício geralmente desfavorável para o indivíduo idoso, os MPI são aqueles que devem ser evitados ou usados com cautela nessa faixa etária (ASSATO; BORJA-OLIVEIRA, 2015). Isso significa que sua classificação como MPI não configura uma contraindicação absoluta para o uso em idosos (MANN et al., 2012). Admite-se que há casos em que um MPI pode ser a alternativa mais adequada. Entretanto, a prescrição de medicamentos desse grupo requer considerar primeiramente, além da relação 
risco-benefício, a disponibilidade de agentes alternativos e de recursos não farmacológicos, e ainda a escolha da menor dose necessária, as potenciais interações medicamentosas e o monitoramento dos efeitos no paciente (ASSATO; BORJA-OLIVEIRA, 2015).

A disponibilidade de agentes alternativos, farmacológicos ou não, está diretamente relacionada à classificação de um MPI. É considerada potencialmente inapropriada a prescrição de um medicamento que apresenta um risco significante de evento adverso, quando há evidência de alternativa igual ou mais efetiva, disponível e com menor risco para tratar a mesma condição (GALLAGHER; BARRY, O'MAHONY, 2007; OLIVEIRA et al., 2016).

\section{6 - ACESSO A MEDICAMENTOS NA REDE PUBLICA}

O sistema público tem vivenciado mudanças significativas desde a criação do SUS, princípios importantes como universalidade do acesso, integralidade da atenção e equidade vêm norteando a política de saúde do país (ROSA; LABATE, 2005). A porta de entrada para o SUS é a Atenção Primária à Saúde (APS) sendo esta a ordenadora das práticas de atenção com um modelo assistencial que considera o paciente como um ser integral que está inserido em um contexto familiar e sociodemográfico (GOLDBAUM et al., 2005). A distribuição de medicamentos na APS é parte integrante do processo de cura, reabilitação e prevenção de doenças.

As políticas de saúde atuais, como a Política Nacional de Medicamentos e o Pacto pela Saúde, tem como prioridade garantir, o acesso a medicamentos essenciais com qualidade e segurança à população (ROZENFELD, 2003).

Segundo a Organização Mundial da Saúde (OMS, 2002), os medicamentos distribuídos na atenção primária são definidos como medicamentos essenciais e que satisfazem as necessidades de cuidados de saúde da maioria da população. A OMS recomenda que os governos estabeleçam listas de medicamentos essenciais como política fundamental para a garantia de acesso das populações a medicamentos seguros, eficazes e custo-efetivos, voltados ao atendimento de suas doenças mais prevalentes e que estejam disponíveis em quantidades adequadas (VIEIRA, 2008). Atualmente, à medida que aumenta a demanda da saúde, devido ao envelhecimento das populações, também se elevam os custos para garantir o acesso a medicamentos. 
No Brasil, existe um financiamento através do SUS que garante o acesso e fornecimento de medicamentos realizado pela rede pública (OLIVEIRA; BERMUDEZ; OSORIO-DE-CASTRO, 2007).

O Ministério da Saúde é responsável pela elaboração e publicação da Relação Nacional de Medicamentos (RENAME), lista com os medicamentos essenciais para tratar as doenças mais comuns na população. Com base nela, estados e municípios constroem sua própria relação de medicamentos (BRASIL, 2011).

A REMUME-SP (Relação Municipal de Medicamentos do Município de São Paulo), referencial para prescrição nos serviços de APS, contém uma lista de medicamentos disponibilizados na rede pública. Os medicamentos disponibilizados na APS para a população são escolhidos considerando o perfil de prevalência de doenças de uma localidade. Estas relações de medicamentos são definidas considerando os estudos que comprovem sua eficácia e segurança, com a melhor relação custo-benefício (MARIN et al., 2003) Alguns dos medicamentos selecionados, embora efetivos e seguros para uma faixa etários da população, podem ser potencialmente inadequados para uso em idosos.

O envelhecimento populacional no Brasil tem gerado novas demandas, que requerem um planejamento dos sistemas de saúde públicos para atender às necessidades específicas dos idosos. Grande parte dos idosos possui alguma doença crônica, o que leva a uma maior utilização de serviços de saúde e a um elevado consumo de medicamentos (ROZENFELD, 2003).

A avaliação do acesso aos medicamentos realizada pela Pesquisa Nacional sobre Acesso, Utilização e Promoção do Uso Racional no Brasil (PNAUM, 2015) verificou que $59,8 \%$ dos usuários declararam ter acesso total a medicamentos nas unidades dispensadoras do SUS, sendo o acesso total maior na região Sudeste (64,3\%) (ÁLVARES et al, 2017).

O estudo SABE (Saúde, Bem-estar e Envelhecimento), realizado em 2007, evidencia que, em São Paulo, 84,3\% dos idosos utilizam medicamento (CARVALHO et al., 2012). O número de idosos utilizando medicamentos em outras cidades brasileiras variou entre $69,1 \%$ a $85 \%$. A terceira idade pode ser considerada o grupo etário mais medicalizado da sociedade (ROZENFELD; FONSECA; ACURCIO, 2008).

\section{7 - PRESCRIÇÃO INAPROPRIADA DE MEDICAMENTOS}

Como já discutido neste trabalho, embora os recursos medicamentosos sejam, em muitos casos, a estratégia mais eficaz, seu uso em idosos também pode oferecer uma relação 
risco-benefício desvantajosa e com repercussões negativas quanto ao estado de saúde (SILVA et al., 2012). Isso ocorre porque algumas condições clínicas requerem o emprego de agentes que se, por um lado, melhoram o quadro clínico, por outro, sujeitam os pacientes a efeitos adversos. A avaliação da relação risco-benefício é, portanto, um dos maiores desafios enfrentados pela terapêutica (ASSATO; BORJA-OLIVEIRA, 2015).

A Prescrição Potencialmente Inapropriada (PPI) é definida como a prescrição de um fármaco por profissional habilitado, que apresenta risco de causar um evento adverso, mesmo com alternativas eficazes disponíveis. Também são consideradas PPI a utilização de medicamentos por tempo maior que o necessário, as interações entre medicamento-doença e medicamento-medicamento, ou até mesmo a subutilização ou não prescrição de fármacos indicados (MANSO; BIFFI; GERARDI, 2015).

As prescrições inapropriadas impactam de forma negativa na saúde e na qualidade de vida dos idosos, por sua vez, colaboram para o aparecimento de interações medicamentosas e efeitos colaterais indesejáveis. É importante considerar que não há segurança total no uso dos fármacos, e mais da metade das iatrogenias sofridas por pacientes idosos tem relação com a terapêutica (MANSO; BIFFI; GERARDI, 2015).

Desta forma deve-se considerar a importância do conhecimento pelos profissionais, das influências que um fármaco pode exercer sobre o outro quando utilizados concomitantemente, sendo o uso racional um fator determinante para minimizar ou evitar a interação medicamentosa (GARSKE et al., 2018).

Define-se como o uso racional de medicamentos a adequação da medicação às necessidades clínicas, em doses ajustadas as características do paciente e em regime terapêutico, tempo e custo-adequados. No Brasil, o uso irracional de medicamentos é um problema de saúde pública, por ocasionar iatrogenia e reações adversas devido a polifarmácia, automedicação e interações medicamentosas (PINTO; FERRÉ; PINHEIRO, 2012).

Em consequência do uso prescrito e não prescrito de medicamentos, as reações adversas tornaram-se uma das principais causas de admissão em serviços de saúde e um grande problema de saúde pública. Como já exposto, os MPIs para idosos, são considerados inadequados devido as alterações na farmacocinética e farmacodinâmica nesta faixa etária, falta de evidências acerca da eficácia terapêutica e pelo risco aumentado de eventos adversos que supera os benefícios (CASSONI et al., 2014). Muitos países implementaram em sua prática clínica instrumentos desenvolvidos para a prevenção de reações adversas e para o cuidado com o uso de MPI. Atualmente, a utilização desses instrumentos tem grande impacto 
nos serviços e auxiliam os profissionais da área da saúde a atuar de forma interdisciplinar e com qualidade na atenção à saúde do idoso (OLIVEIRA; CORRADI, 2018).

A fim de reduzir a PPI, as ocorrências de iatrogenia medicamentosa e ainda orientar a escolha da melhor terapêutica, foram desenvolvidas listas padronizadas de medicamentos classificados de acordo com riscos e benefícios gerados, isto é, listas de MPI. Entre as mais utilizadas estão os Critérios de Beers e os Critérios STOPP e START (O'Mahony et al., 2015; ROSA et al., 2016).

Os critérios de Beers (AGS, 2019) são representados por meio de uma relação de fármacos, periodicamente ampliada e revisada pela Sociedade Americana de Geriatria, composta por MPI para idosos por ineficácia ou alto risco de eventos adversos. Estes critérios servem como "alerta" para identificar medicamentos que apresentam um saldo desfavorável entre benefícios e risco em muitos idosos, particularmente quando comparados com alternativas farmacológicas e não farmacológicas. São chamados de "potencialmente inapropriados" justamente porque, como destacado anteriormente, existem situações em que a indicação da prescrição do medicamento pode ser apropriada. Este tipo de prescrição realmente merece uma avaliação cuidadosa do prescritor, mas não é totalmente inapropriada em todos os pacientes idosos (STEINMAN et al, 2015).

Com a finalidade de suprir as possíveis deficiências dos Critérios de BEERS, foi desenvolvido na Irlanda em 2003 os critérios STOPP (Screening Tool of Older Person's Prescriptions) e START (Screening Tool to Alert doctors to Right Treatment). Os critérios de STOPP-START reconhecem por avaliação explícita os erros mais comuns de tratamento e omissão na prescrição. São denominados STOPP os medicamentos considerados potencialmente inapropriados (MPI) e denominados START os medicamentos potencialmente omitidos (MPO). O medicamento potencialmente omitido é definido como aquele que é considerado primordial para o sucesso do tratamento medicamentoso garantindo sua eficácia e segurança (O'MAHONY et al., 2015; ROSA et al., 2016).

Uma das maiores dificuldades identificadas pelos médicos de família (MF) é a interrupção de medicação iniciada por outro médico especialista. Sem uma linha de comunicação clara, a decisão do custo-benefício da manutenção da prescrição pode não ser fácil. A revisão terapêutica deve ser frequente e a existência de instrumentos que podem ajudar na "deprescrição" como o STOPP-START (Screening Tool of Older Person's Potentially Inappropriate Prescriptions-Screening Tool of Alert doctors to the Right Treatment) ou o PROMPT (Prescribing Optimally in Middle-aged People's Treatments) (REIS; CARDOSO, 2015). 
A maior fragilidade no desenvolvimento dessas ferramentas de alerta de MPI é o fato de que muitos fármacos contidos nos critérios desenvolvidos não são comercializados em todos os países. Entre os países, há diferenças tanto em disponibilidade de fármacos quanto em condutas prescritivas adotadas. Por esse motivo, esses instrumentos têm sido adaptados em muitos países. Alguns exemplos são os critérios elaborados na Irlanda, Screening Tool of Older Persons' Prescriptions (STOPP) (GALLAGHER et al., 2008), no Canadá (MCLEOD et al., 1997), na Áustria (MANN et al., 2012), na Coréia (KIM et al., 2010), na França (LAROCHE; CHARLES; MERLE, 2007) e na Alemanha (HOLT; SCHMIEDL; THURMANN, 2010).

Diante dessa necessidade, tendo como ponto de partida os critérios de Beers e o STOPP, foi desenvolvido no Brasil o primeiro Consenso Brasileiro de Medicamentos Potencialmente Inapropriados para Idosos (OLIVEIRA et al, 2016), do qual os participantes foram profissionais da área clínica/experts brasileiros, profissionais e pesquisadores da área gerontológica, geriátrica e clínica, de diferentes áreas geográficas do país. O Consenso Brasileiro de MPI (CBMPI), que tem o intuito de guiar os profissionais de saúde no cuidado ao paciente idoso, apresenta critérios de medicamentos que devem ser evitados em idosos independentemente da condição clínica e os que dependem da condição clínica (OLIVEIRA et al, 2016).

O CBMPI é o primeiro estudo brasileiro de impacto, voltado para a comercialização e prevalência dos principais medicamentos prescritos na prática clínica do país. Este instrumento tornou-se a solução para carência de critérios adaptados a prática clínica do país, visto que muitos estudos utilizam, principalmente os critérios de Beers para análise de grupos de idosos (OLIVEIRA; CORRADI, 2018).

Evitar o uso de MPI para idosos é uma importante estratégia de saúde pública. Em muitos países, os instrumentos para identificação de MPI para idosos foram fundamentais para melhorar a postura de prescrição apropriada para essa população e reduzir os desfechos negativos relacionados à farmacoterapia nessa população, como reações adversas preveníveis, hospitalizações, incapacidades e morte (SÖNNICHSEN, et al, 2016; OLIVEIRA et al., 2016).

Em um estudo transversal recente (LUTZ; MIRANDA; BERTOLDI, 2017), de base populacional, realizado em Pelotas, RS, com 1.451 idosos, 42,4\% deles utilizava no mínimo um MPI. O instrumento utilizado para identificação de MPI foram os critérios de Beers, a ferramenta norte-americana. Os autores desse estudo chamaram a atenção para o fato de que os profissionais devem conhecer as possíveis consequências do uso desses medicamentos nessa faixa etária e recomendaram uma maior ênfase nos currículos das 
faculdades sobre as especificidades do uso de medicamentos entre idosos, informando os futuros profissionais sobre prescrições potencialmente inadequadas para essa faixa etária.

O uso de MPI tem apresentado associação positiva com o uso de polifarmácia (NASSUR et al., 2010; LOPES et al., 2016; MAGALHÃES et al., 2020). Com base nesse contexto, o objetivo desta pesquisa foi estimar prevalência da prescrição de MPI e sua associação com polifarmácia, idade e sexo, entre idosos usuários das unidades da APS, bem como apontar alternativas farmacológicas que façam parte da REMUME-SP. 


\section{JUSTIFICATIVA}

O envelhecimento populacional tem nos motivado a buscar formas de contribuir com a adequação dos serviços às demandas do indivíduo idoso. Nesse sistema, a velhice e o envelhecimento não são prioridade. Essa situação fica ainda pior com a falta de profissionais apropriadamente qualificados para atender e tratar de modo adequado o idoso em todos os níveis de atenção (BRASIL, 2006), e com o fato de as diretrizes se basearem em ensaios clínicos que excluem indivíduos idosos e com múltiplas doenças crônicas (REIS; CARDOSO, 2015).

Nesse contexto, que é desfavorável ao atendimento adequado do usuário idoso, os estudos sobre utilização de medicamentos assumem maior importância, pois permitem conhecer o perfil de uso de medicamentos de uma população e são estratégicos para identificar a prevalência da prescrição inapropriada. A presente pesquisa justifica-se pela necessidade de estimar essa prevalência entre idosos acompanhados nos serviços de atenção primária.

Em idosos, o uso de MPI, com ou sem prescrição, pode por elevar o risco de quedas, bem como causar retenção urinária, constipação, distúrbios gástricos, distúrbios visuais, declínio cognitivo, cascata iatrogênica e outros desfechos negativos.

A identificação da prescrição inapropriada e de sua origem é fundamental para justificar e orientar intervenções que possam tornar o uso de medicamentos mais racional e evitar problemas relacionados a medicamentos. 


\section{OBJETIVO}

O objetivo desta pesquisa foi estimar a prevalência da prescrição de MPI e sua associação com polifarmácia, idade e sexo, entre idosos usuários das unidades da APS, bem como apontar alternativas farmacológicas integrantes da REMUME-SP 2016. 


\section{MATERIAIS E MÉTODOS}

\subsection{DESENHO, LOCAL DO ESTUDO E PERÍODO}

Neste estudo transversal, descritivo e analítico, de abordagem quantitativa, constituíram locais de locais de coleta três Unidades de Saúde pertencentes à Secretaria Municipal de Saúde de São Paulo. Foram utilizados os dados de usuários idosos (com 60 anos ou mais), coletados entre 2016 e 2019, armazenados em um banco de dados.

\subsection{POPULAÇÃO, CRITÉRIOS DE INCLUSÃO E EXCLUSÃO}

Os participantes da amostra, cujos dados compuseram o banco de dados, foram idosos ou seus representantes, usuários da farmácia da Unidade de Saúde participante da pesquisa, munidos da prescrição, que concordaram em participar da pesquisa durante o período de coleta de dados. A participação se deu de forma voluntária.

Critérios de inclusão: Foram incluídas todas as prescrições para indivíduos de 60 anos ou mais apresentadas no balcão da farmácia das Unidades de Saúde participantes da amostra, nos dias programados para a coleta de dados, independentemente de sua origem ou da disponibilidade ou não dos medicamentos prescritos na rede. É importante ressaltar que o objeto de pesquisa foram as prescrições e não os indivíduos, pois um indivíduo de outro grupo etário portando receita de um idoso (com 60 anos ou mais) atendeu aos critérios de inclusão e, portanto, esta prescrição pôde integrar a amostra.

Critérios de exclusão: Excluiu-se todas as outras prescrições não referentes a indivíduos com 60 anos ou mais, ou apresentadas fora do período de coleta de dados.

\subsection{DADOS COLETADOS E INSTRUMENTOS DE COLETA}

Nos casos em que o usuário apresentou a receita em duas vias, uma delas permaneceu na farmácia, para posterior coleta dos dados de interesse para a pesquisa. Quando apenas uma via da receita foi apresentada, o profissional da farmácia realizou a transcrição dos dados de interesse. Portanto, os procedimentos envolvidos na pesquisa consistiram apenas em registro de dados. 
Para a coleta de dados, foi utilizado um formulário previamente estruturado (ANEXO 1), no qual foram registrados os medicamentos prescritos, idade, sexo e tipo de serviço que gerou a prescrição.

Como alguns medicamentos são considerados potencialmente inapropriados a partir de certa dose e/ou certo período de tratamento, também se registrou, para fins de análise quanto à inapropriação, a dose prescrita, a posologia e o tempo de duração do tratamento. Estes dados foram, portanto, utilizados meramente para determinar se certas prescrições eram consideradas potencialmente inapropriadas.

\subsection{ANÁLISE DOS DADOS}

O instrumento de análise dos dados utilizado foi o CBMPI (OLIVEIRA et al., 2016). Tal instrumento apresenta listas de medicamentos que são considerados inapropriados dependendo das condições clínicas do idoso e também listas contendo os que são inapropriados para idosos independentemente das condições clínicas dos mesmos. Nesta pesquisa, como as condições clínicas dos participantes não foram coletadas, apenas a lista de MPI independentes das condições clínicas foi utilizada (Anexo 2). O Quadro 1 do CBMPI é a parte do instrumento que apresenta as listas de MPI que independem da condição clínica do idoso, isto é, devem ser evitados em todos os idosos.

Os MPI encontrados foram confrontados com a Relação Municipal de Medicamentos Essenciais de São Paulo (REMUME-SP) mais atualizada (2016). Com base na literatura (HANLON; SEMLA; SCHMADER, 2015; RENOM-GUITERAS; MEYER; THÜRMANN, 2015, AGS, 2019, MOTTER; HILMER; PANIZ, 2019) e também no CBMPI, foram indicadas alternativas terapêuticas aos MPI identificados. Entre as alternativas farmacológicas encontradas, selecionou-se as integrantes da REMUME.

A análise descritiva dos dados foi realizada determinando, para as variáveis quantitativas, medidas de tendência central (mediana) e de dispersão (intervalo interquartil IIQ). A opção por apresentar mediana e IIQ no lugar de média e desvio-padrão se deu com base no teste de normalidade de D'Agostino-Pearson, desenvolvido para lidar com amostras numerosas ( $\mathrm{n}>$ 100) (MIOT, 2017). Este teste demonstrou que os dados obtidos nesta pesquisa não apresentavam distribuição normal, o que torna a apresentação de mediana e IIQ mais apropriada. Para as variáveis categóricas, foi realizada a distribuição de frequência e porcentagens (frequências absoluta e relativa). 
Além das prevalências, foi estimada a associação entre variáveis por análise bivariada, utilizando-se a razão de prevalência (RP), seus intervalos de confiança (IC95\%), teste Quiquadrado de Pearson e um nível de significância de 5\%. A análise dos dados foi realizada no IBM SPSS Statistics.

\subsection{ASPECTOS ÉTICOS}

O estudo foi aprovado pelo Comitê de Ética e Pesquisa do Hospital Santa Marcelina Itaquera e posteriormente pelo Comitê de Ética em Pesquisa da Secretaria Municipal de Saúde de São Paulo sob o parecer 604.704-0 e CAAE 23238513.0.3001.0086.

A participação na pesquisa foi precedida pela assinatura do Termo de Consentimento Livre e Esclarecido (ANEXO 3) pelos pacientes e/ou acompanhantes. 


\section{RESULTADOS}

Participaram da pesquisa 562 usuários, cuja idade registrada variou entre 60 e 90 anos de idade. Daqueles para os quais a idade foi informada no formulário de coleta de dados (548 participantes), a maioria $(n=330 ; 60,3 \%)$ possuía entre 60 e 69 anos (Tabela 1). A mediana da idade foi 68 (IIQ = 63-73).

Dos 556 participantes para os quais o sexo foi informado no formulário, a maior parte $(\mathrm{n}=363 ; 65,3 \%)$ era do sexo feminino (Tabela 1$)$.

Os participantes possuíam entre 1 e 12 medicamentos em suas prescrições. Quase metade dos 562 participantes da pesquisa $(n=277 ; 49,3 \%)$ apresentaram prescrições de cinco ou mais medicamentos (Tabela 1). A mediana de medicamentos prescritos foi 4 (IIQ = 3-6).

Dos 562 participantes, $307(54,6 \%)$ possuíam uma ou mais prescrições de MPI. O número de MPI prescritos para esses participantes variou entre 1 e 5 (Tabela 1), com uma mediana de $1(\mathrm{IIQ}=1-2)$.

Tabela 1. Prevalências e IC $95 \%$ das variáveis estudadas em usuários da atenção primária. São Paulo, 2016 - 2019.

\begin{tabular}{|c|c|c|}
\hline Variável & n (\%) & IC95\% \\
\hline \multicolumn{3}{|l|}{ Sexo $^{\mathbf{a}}$} \\
\hline Feminino & $363(65,3)$ & $61,3-69,2$ \\
\hline Masculino & $193(34,8)$ & $30,8-38,7$ \\
\hline \multicolumn{3}{|c|}{ Faixa etária $(\text { anos) })^{a}$} \\
\hline $60-69$ & $330(60,3)$ & $56,1-64,3$ \\
\hline$\geq 70$ & $218(39,8)$ & $35,7-43,9$ \\
\hline \multicolumn{3}{|c|}{ Número de medicamentos prescritos } \\
\hline $1-4$ & $285(50,8)$ & $46,6-54,8$ \\
\hline$\geq 5$ & $277(49,3)$ & $45,2-53,4$ \\
\hline \multicolumn{3}{|c|}{ Possui prescrição de MPI } \\
\hline Não & $255(45,4)$ & $41,3-49,5$ \\
\hline Sim & $307(54,6)$ & $50,5-58,7$ \\
\hline \multicolumn{3}{|c|}{ Número de MPI prescritos } \\
\hline 0 & $254(45,2)$ & $41,1-49,3$ \\
\hline 1 & $221(39,4)$ & $35,3-43,4$ \\
\hline 2 & $61(10,9)$ & $8,3-13,4$ \\
\hline $3-5$ & $26(4,7)$ & $2,9-6,4$ \\
\hline
\end{tabular}

Tabela elaborada pelos próprios autores. ${ }^{a}$ Excluídos os casos em que não houve preenchimento das informações relacionadas a estas variáveis. IC - Intervalo de Confiança. MPI - Medicamentos Potencialmente Inapropriados para Idosos. 
Como mostra a Tabela 2, houve associação estatisticamente significativa entre polifarmácia (consumo de 5 medicamentos ou mais) e prescrição de MPI (RP = 1,87; IC95\% $=1,59-2,20 ; \mathrm{p}<0,0001)$, indicando que a polifarmácia quase dobra o risco de prescrição de MPI. Não foi encontrada associação entre prescrição de MPI com sexo e idade.

Tabela 2. Associação entre prescrição de MPI e as variáveis estudadas entre usuários das unidades de atenção primária. São Paulo, São Paulo, 2016 - 2019.

\begin{tabular}{lccc}
\hline Variável & $\mathbf{n}(\mathbf{\%})$ & RP $(\mathbf{I C 9 5} \%)$ & p-valor\# \\
\hline Sexo & & & 0,175 \\
\hline Feminino & $208(55,8)$ & $1,12(0,95 ; 1,32)$ & \\
$\quad$ Masculino & $99(56,4)$ & 1,00 & \\
\hline Faixa etária (anos) & & & \\
$\quad 60-69$ & $184(86,8)$ & $0,99(0,85 ; 1,15)$ & \\
$\quad \geq 70$ & $123(87,8)$ & 1,00 & \\
\hline Número de medicamentos prescritos & & & $<\mathbf{0 , 0 0 0 1}$ \\
$\quad 1-4$ & $110(38,6)$ & 1,00 & \\
$\geq 5$ & $200(72,2)$ & $1,87(1,59 ; 2,20)$ & \\
\hline
\end{tabular}

Tabela elaborada pelos próprios autores. "\#Teste qui-quadrado de Pearson. RP - Razão de Prevalência; IC Intervalo de Confiança.

Os MPI mais prevalentes foram o inibidor da bomba de prótons (protetor gástrico) omeprazol, prescrito para 181 participantes (32,2\% dos 562 participantes desta pesquisa), o antidiabético glibenclamida $(\mathrm{n}=59 ; 10,5 \%)$ e o diurético furosemida $(\mathrm{n}=49 ; 8,7 \%)$. Os antiinflamatórios não esteroidais (AINES) foram prescritos para $42(7,4 \%)$ participantes.

Os MPI foram confrontados com a REMUME-SP e observou-se que 93,3\% ( $\mathrm{n}=28)$ deles constava nessa lista. As exceções foram a ciclobenzaprina e o ácido acetilsalicílico de $500 \mathrm{mg}$.

Uma vez que parte dos 310 portadores de prescrição de MPI possuía mais de um MPI em sua prescrição, identificou-se um total de 422 prescrições, descritas na Tabela 3, a qual apresenta, além dos 30 MPI prescritos, o número de prescrições de cada classe terapêutica à qual cada um pertence, as justificativas que restringem seu uso em idosos e as alternativas terapêuticas indicadas na literatura, cujas opções farmacológicas integram a REMUME do município de São Paulo.

As alternativas incluídas na Tabela 3 são as indicadas nas fontes consultadas, apontadas nos métodos deste trabalho, e que faziam parte da REMUME-SP. Essas fontes apresentavam alternativas farmacológicas para 16 (53,3\%) dos 30 MPI utilizados pelos usuários da amostra. Alternativas não farmacológicas também foram indicadas. Como mostra 
a Tabela 3, não foram encontradas, nas fontes consultadas, alternativas para todos os MPI identificados.

Tabela 3. Prevalência de MPI prescritos aos participantes da pesquisa, justificativas para a restrição em idosos e alternativas terapêuticas. São Paulo, 2016 - 2019.

\begin{tabular}{llcc}
\hline Medicamentos & $\begin{array}{l}\text { Restrição em idosos\# } \\
\text { alternativas mais seguras+ }\end{array}$ & IC95\% \\
\hline IBP & & $\mathbf{1 8 1}(\mathbf{3 2 , 2})$ & $\mathbf{2 8 , 3 - \mathbf { 3 6 , 1 }}$ \\
\hline Omeprazol & $\begin{array}{l}\text { Potencial para desenvolvimento de osteoporose/fratura, } \\
\text { demência e insuficiência renal com o uso prolongado. }\end{array}$ \\
& $\begin{array}{l}\text { Descontinuação antes de oito semanas de uso ou redução da } \\
\text { dose para tratamento, manutenção/profilático de úlcera } \\
\text { péptica, esofagite ou doença do refluxo gastroesofágico. }\end{array}$
\end{tabular}

Antidiabéticos

$59(10,5) \quad 8,0-13,0$

Glibenclamida

Maior risco de hipoglicemia prolongada grave. Alternativas: reeducação alimentar, metformina, gliclazida.

Diuréticos de alça

$49(8,7)$

$6,4-11,1$

Furosemida

Para edema de tornozelo, na ausência de sinais clínicos de insuficiência cardíaca, não há evidência da eficácia. Alternativas: Meias de compressão geralmente são mais apropriadas.

Ibuprofeno

Diclofenaco

AAS (aspirina) em dose > $150 \mathrm{mg} / \mathrm{dia}$
Aumentam o risco de hemorragia gastrointestinal e úlcera péptica em grupos de alto risco, incluindo aqueles com idade $>75$ anos ou que utilizam corticosteroides orais ou parenterais, anticoagulantes ou antiplaquetários. O uso de inibidor da bomba de prótons reduz, mas não elimina o risco. Evitar uso crônico, exceto quando não houver outras alternativas e for possível associação com agente gastroprotetor. Alternativas: paracetamol, dipirona, recursos não-farmacológicos (como fisioterapia, acupuntura, termoterapia, eletroestimulação e massagem terapêutica). 
Tabela 3. Prevalência de MPI prescritos aos participantes da pesquisa, justificativas para a restrição em idosos e alternativas terapêuticas. São Paulo, 2016 - 2019 (continuação).

\begin{tabular}{lcc}
\hline Benzodiazepínicos & $12(2,1)$ & $0,9-3,3$ \\
\hline
\end{tabular}

Clonazepam

Diazepam
Em geral, os benzodiazepínicos aumentam o risco de comprometimento cognitivo, delirium, quedas, fraturas e acidentes automobilísticos. Evitar todos os benzodiazepínicos para tratar insônia, agitação ou delirium. Alternativas: antidepressivos com perfil ansiolítico (inibidores seletivos da recaptação de serotonina: fluoxetina, sertralina), recursos não farmacológicos.
Anti-histamínicos de $1^{\text {a }}$ geração

Dexclorfeniramina

Prometazina

Dimenidrinato

Hidroxizina
Risco de sedação e efeitos anticolinérgicos (confusão, boca seca, constipação, entre outros). Há o desenvolvimento de tolerância, quando utilizados como hipnóticos. Alternativas (dependendo da condição tratada): loratadina, salina intranasal e esteroides intranasais.

Alfa-agonistas de ação central

$10(1,8)$

$0,7-2,9$

Metildopa
Digoxina $>0,125 \mathrm{mg} / \mathrm{dia}$

\section{Digitálicos}

Alto risco de efeitos adversos ao sistema nervoso central. Podem causar bradicardia e hipotensão ortostática. Alternativas: antagonistas do receptor da angiotensina II (losartana), inibidores da ECA (captopril, enalapril), bloqueadores dos canais de cálcio (anlopidino), diuréticos tiazídicos (hidroclorotiazida).

A diminuição do clearance renal com o envelhecimento aumenta o risco de intoxicação digitálica. Além disso, na insuficiência cardíaca, as doses mais altas elevam o risco de toxicidade e não oferecem maiores benefícios. Alternativas: Para taquicardia e fibrilação atrial, beta bloqueadores seletivos (atenolol, metoprolol). Para insuficiência cardíaca congestiva, diuréticos (hidroclorotiazida) e inibidores da ECA (captopril, enalapril).

\section{Amitriptilina} Imipramina
Altamente anticolinérgicos, sedativos e causam hipotensão ortostática.

Alternativas: inibidores seletivos da recaptação de serotonina (fluoxetina, sertralina), recursos não farmacológicos. 
Tabela 3. Prevalência de MPI prescritos aos participantes da pesquisa, justificativas para a restrição em idosos e alternativas terapêuticas. São Paulo, 2016 - 2019 (continuação).

\begin{tabular}{ll}
\hline Antiarrítmicos & \multicolumn{5}{c}{$\mathbf{5 ( 0 , 9 )}$} \\
\hline \multirow{2}{*}{ Amiodarona } & Dados sugerem que o controle da frequência cardíaca \\
& proporciona melhor perfil risco-benefício do que o controle \\
& do ritmo em idosos. A amiodarona está associada a doenças \\
& da tireóide, distúrbios pulmonares e prolongamento do \\
& intervalo QT.
\end{tabular}

\begin{tabular}{ll}
\hline Antipsicóticos & \multicolumn{1}{c}{$\mathbf{5}(\mathbf{0 , 9})$} \\
\hline Risperidona & Aumento do risco de acidente vascular cerebral (AVC) e \\
Clorpromazina & mortalidade. \\
Quetiapina & Alternativas: com exceção de casos como esquizofrenia e \\
& transtorno bipolar, antipsicóticos devem ser evitados em \\
& idosos. Não se deve empregá-los no tratamento dos sintomas \\
& comportamentais da demência e no delirium, a menos que os \\
& recursos não farmacológicos tenham falhado ou não sejam \\
& possíveis e o paciente represente ameaça para si ou para \\
& outros.
\end{tabular}

Barbitúricos

$4(0,7)$

Fenobarbital

Alta proporção de dependência física, tolerância na indução do sono e risco de overdose em doses baixas.

\section{Laxativo emoliente}

Óleo mineral (via oral)

\section{$4(0,7)$}

Potencial para aspiração e efeitos adversos. Alternativas mais seguras disponíveis. Alternativas: reeducação alimentar com o aumento da ingestão de fibras e fluidos.
Xantinas

Teofilina

\section{$3(\mathbf{0 , 5})$}

Existência de alternativa mais segura e efetiva. Além disso, risco de efeitos adversos devido ao índice terapêutico estreito.

\begin{tabular}{lll}
\hline Antiespasmódicos gastrointestinais & $3(0,5)$ & - \\
\hline
\end{tabular}

Escopolamina
Altamente anticolinérgico. Efetividade incerta. Evitar, exceto em cuidado paliativo de curto prazo para reduzir secreções orais. 
Tabela 3. Prevalência de MPI prescritos aos participantes da pesquisa, justificativas para a restrição em idosos e alternativas terapêuticas. São Paulo, 2016 - 2019 (continuação).

\begin{tabular}{ll}
\hline Propulsivos & $\mathbf{2}(\mathbf{0 , 3})$ \\
\hline Metoclopramida & $\begin{array}{l}\text { Pode causar efeitos extrapiramidais incluindo discinesia } \\
\text { tardia. Risco pode ser ainda maior em idosos mais frágeis. }\end{array}$
\end{tabular}

\begin{tabular}{lll}
\hline Antiparkinsonianos com forte ação anticolinérgica & $1(0,2)$ & - \\
\hline
\end{tabular}

Biperideno

Risco de toxicidade anticolinérgica. Alternativa: levodopa.

Relaxantes musculares

$1(\mathbf{0 , 2})$

Ciclobenzaprina $\quad$ A maioria dos relaxantes musculares é pouco tolerada por idosos devido aos efeitos anticolinérgicos, como sedação, e consequente risco de fratura. A efetividade em doses toleradas por idosos é questionável.

Alternativas: paracetamol, recursos não-farmacológicos (como fisioterapia, acupuntura, termoterapia, eletroestimulação e massagem terapêutica).

*Referente aos 562 participantes da pesquisa; desses, 310 receberam uma ou mais prescrições de MPI, o que resultou nas 422 prescrições apresentadas na Tabela. \#Informações extraídas do CBMPI. +Baseado em Hanlon, Semla \& Schmader (2015), Renom-Guiteras, Meyer, \& Thürmann (2015), AGS (2019), Motter, Hilmer \& Paniz (2019) e CBMPI. IBP - Inibidores de bomba de prótons. AINES - Antiinflamatórios não esteroidais. AAS - ácido acetilsalicílico. IC - Intervalo de Confiança. 


\section{DISCUSSÃO}

No presente estudo, observou-se que mais da metade (55\%) dos usuários participantes possuía prescrição de MPI. Essa prevalência é semelhante àquela encontrada em um estudo recente que analisou a frequência de MPI na prescrição de alta hospitalar de 255 idosos de um hospital público, também com base no CBMPI (MAGALHÃES; SANTOS; REIS, 2019). Nessa pesquisa, o inibidor da bomba de prótons omeprazol também foi o MPI mais prescrito, integrando a prescrição de $37 \%$ dos pacientes participantes, índice muito próximo ao encontrado no presente estudo (32\%). O uso prolongado de inibidores da bomba de prótons está associado ao desenvolvimento de osteoporose/fratura, demência e insuficiência renal em idosos (OLIVEIRA et al., 2017).

Outros MPI mais prevalentes foram o antidiabético glibenclamida, o diurético furosemida e os da classe dos AINEs. Enquanto a glibenclamida pode causar hipoglicemia grave em idosos (OLIVEIRA et al., 2017), a furosemida pode ter seu efeito intensificado em função da redução da função renal nessa faixa etária e provocar hipotensão ortostática, elevando o risco de quedas (MILOS et al., 2014). Por sua vez, os AINEs aumentam o risco de hemorragia gastrointestinal e úlcera péptica (OLIVEIRA et al., 2017).

A prevalência de uso de MPI foi superior à encontrada em estudos recentes que analisaram a frequência de MPI na APS, sendo 42\% em Pelotas - RS (LUTZ, MIRANDA, BERTOLDI, 2017), 43,8\% em Viçosa - Minas Gerais (MARTINS et al,2015), 53,66\% em Santa Cruz do Sul - RS (GARSKE et al.,2018) e 41\% em Diamantina, Minas Gerais (ARAUJO et al., 2019).

Observou-se que 93\% dos MPI identificados nesta pesquisa constavam na REMUMESP, dado que aponta para a necessidade de se incluir nos protocolos clínicos da Relação Nacional (RENAME) as restrições para uso desses medicamentos em idosos constantes no CBMPI. Embora a REMUME-SP, em sua relação padronizada, tenha o propósito de constituir as melhores opções farmacoterapêuticas (relação custo, eficácia, segurança e comodidade de uso) para as várias faixas etárias da população, muitos dos medicamentos padronizados pelo município são considerados MPI. Contudo, a lista integra certas alternativas supostamente mais seguras, cujas opções farmacológicas indicadas na literatura (HANLON; SEMLA; SCHMADER, 2015; OLIVEIRA et al., 2017; RENOM-GUITERAS; MEYER; THÜRMANN, 2015, AGS, 2019, MOTTER; HILMER; PANIZ, 2019) foram apontadas neste trabalho. 
Apontar alternativas integrantes da RENAME e, sobretudo, acrescentar alternativas a essa lista, é estratégico para reduzir o uso de MPI, pois os idosos, em sua maioria, possuem significativa dependência dos medicamentos disponibilizados de forma gratuita pelo SUS. Pela mesma razão, há necessidade do emprego de ferramentas que orientem os prescritores na escolha da terapêutica dos pacientes idosos (GARSKE et al., 2018) - uma lista que aponte não apenas MPI mas também agentes alternativos constitui um instrumento potencialmente útil nesse contexto.

Tais ferramentas não devem se limitar a alternativas farmacológicas. Neste estudo, observou-se que boa parte das alternativas apontadas na literatura não são medicamentosas, como a acupuntura, que integra a Política Nacional de Práticas Integrativas e Complementares no SUS (BRASIL, 2015). Sabe-se que estas estratégias - essenciais para reduzir o uso de medicamentos e, portanto, a exposição a eventos adversos - são subutilizadas.

O fato de haver alternativas disponíveis no SUS para mais da metade dos MPI prescritos mostra que não basta disponibilizá-las; é necessário promover conscientização sobre a necessidade de prescrevê-las para o idoso no lugar dos MPI sempre que possível, decisão esta que evidentemente deve ser baseada numa avaliação individualizada do usuário e das condições clínicas a serem tratadas.

A presente pesquisa é um dos poucos estudos a determinar a frequência de uso de MPI na APS empregando o CBMPI. A utilização critérios desenvolvidos na perspectiva dos medicamentos comercializados em um país são importantes, pois propiciam melhor análise do perfil de utilização de MPIs e a fatores associados. Estes critérios proporcionam informações seguras para a prática clínica segura e adoção de políticas públicas que que visam reduzir problemas relacionados à farmacoterapia nos idosos do país (MAGALHAES, SANTOS, REIS, 2020). Além disso, o Consenso apresenta boa concordância com os critérios internacionais, como o AGS Beers 2015 e o European Union List of Potentially Inappropriate Medications (EU) PIM List), evidenciando sua factibilidade para uso em investigações farmacoepidemiológicas e na prática clínica (ALMEIDA et al., 2019).

Neste estudo, a prescrição de MPI mostrou-se associada com polifarmácia, demonstrando que esta quase duplica o risco de prescrição de MPI. A associação entre uso de MPI e polifarmácia tem sido observada em vários estudos (NASSUR et al., 2010; LOPES et al., 2016; MAGALHÃES et al., 2020). O consumo de cinco medicamentos ou mais é, portanto, fator de risco para utilização de MPI.

Quase metade dos participantes desta pesquisa apresentaram prescrições de cinco ou mais medicamentos. Considerando que neste estudo o dado analisado foi o número de 
medicamentos prescritos e não o número de medicamentos consumidos por usuário, a polifarmácia propriamente dita - que inclui a automedicação -, pode ser ainda maior no grupo estudado. Sabe-se que a automedicação é uma prática comum em idosos (SANTOS; NOGUEIRA; BORJA-OLIVEIRA, 2018).

A prevalência de prescrição de cinco ou mais medicamentos observados no presente estudo foi superior à encontrada em outros estudos semelhantes (CARVALHO et al., 2012; PAULA JÚNIOR, 2013; GARSKE, 2018; ARAUJO et al., 2019) e na pesquisa do PNAUM 2015 (Pesquisa Nacional sobre Acesso, Utilização e Promoção do Uso Racional de Medicamentos no Brasil), que demostrou que uma parcela significativa dos idosos do país estão em uso de polifarmácia. Segundo o estudo de Da Silva e Macedo (2013), a média de medicamentos prescritos para idosos varia de dois a cinco medicamentos. Em estudo de Marin e colaboradores (2008), o número de medicamentos por idosos variou entre três e quatro, podendo chegar a doze medicamentos, vindo de encontro com o resultado da presente pesquisa.

Este resultado é decorrente da prática clínica de prescrição de vários medicamentos para múltiplas patologias comuns ao processo de envelhecimento. Para o manejo destas várias condições clínicas, são implantados protocolos clínicos que recomendam a associação de medicamentos, para otimização do tratamento farmacoterapêutico. Porém estas associações podem acarretar prejuízos no cuidado, devido aos riscos de reações adversas e interações medicamentosas, cujos efeitos podem ser confundidos com sintomas de novas condições e/ou enfermidades, levando à prescrição de novos medicamentos e construindo assim uma cascata iatrogênica. (CARVALHO et al., 2012; SANTOS et al., 2020).

A literatura reforça os desfechos negativos da polifarmácia em idosos. No mundo, a média de medicamentos utilizados em todo sistema de saúde é bastante elevada. Este fato é decorrente da atual prevalência de DCNTs comuns na velhice. Nesse contexto, a prática de monitoramento na atenção primária pelas equipes de saúde pode contribuir para reduzir os efeitos colaterais, os riscos das interações medicamentosas e a adesão terapêutica (ARAUJO et al., 2019).

É importante a sensibilização dos médicos sobre os métodos disponíveis para a avaliação de problemas relacionados aos medicamentos, de modo a favorecer a prescrição adequada baseada nas melhores evidências científicas disponíveis, o que contribui para um manejo mais adequado do paciente idoso na APS (OLIVEIRA, BUARQUE, 2018; ARAUJO et al., 2019). 
A alta prevalência de MPI em nosso estudo pode estar relacionada a duas possíveis causas, entre outras: necessidade de utilização de critérios de prescrição para idosos pelos profissionais médicos para redução de prescrições inapropriadas; quantidade insuficiente de alternativas terapêuticas na REMUME-SP que incentivem uma prescrição de medicamentos mais seguros para os idosos.

É importante ainda ressaltar que foi constatado na amostra desta pesquisa um predomínio do gênero feminino. A significativa representatividade do sexo feminino na maioria da população brasileira é reflexo da alta mortalidade masculina nas faixas etárias jovens e adultas, decorrentes das causas violentas. Esta relação se reflete diretamente no perfil da população idosa (MOREIRA, 2014). Segundo Silva (2018), no Brasil, a feminização na velhice é um consenso mundial justificado pela maior longevidade das mulheres em relação aos homens. Esta maior expectativa de vida pode ser explicada pelo fato de as mulheres exercerem funções de trabalho de menor risco, menor uso de álcool e tabaco e possuir maiores cuidados em relação a saúde e o autocuidado.

No município de São Paulo, conforme as informações existentes no SEADE 2017 sobre o perfil dos idosos, destaca-se o predomínio do sexo feminino (60\%) na constituição deste segmento etário (SÃO PAULO, 2019). A grande representatividade feminina encontrada neste trabalho é semelhante àquela observada em outros estudos brasileiros (CARVALHO et al, 2012; LUTZ et al, 2017).

Este estudo limitou-se a analisar as prescrições apresentadas nas farmácias de três Unidades de Saúde pertencentes à Secretaria Municipal de Saúde de São Paulo. São limitações do estudo a ausência de informações sobre as condições clínicas dos idosos participantes e o uso de outros medicamentos, além daqueles que constavam em suas prescrições. Também não foi investigada a adesão às prescrições apresentadas.

Outras limitações deste estudo se referem às alternativas, sobretudo as farmacológicas, indicadas. Nenhuma das fontes consultadas para obtenção de informação sobre alternativas terapêuticas contém indicações de substitutos para todos os MPI e, em alguns casos, as informações são conflituosas, o que impediu a indicação de alternativas para todos os MPI encontrados. Além disso, a prescrição de alternativas, bem como de MPI, depende da condição clínica tratada e da condição clínica do paciente ou usuário, o que inclui a existência de eventuais contraindicações às potenciais alternativas. As próprias fontes consultadas neste trabalho e a literatura em geral assumem que o uso de MPI, mesmo devendo ser evitado em idosos, pode ser apropriado em certas condições. De qualquer modo, uma vez que o uso de MPI é potencialmente iatrogênico e sujeita os idosos a alto risco de eventos 
adversos, é indispensável, em todos os casos, avaliar a relação risco e benefício. A ausência dessa avaliação constitui iatrogenia. 


\section{CONCLUSÃO E CONSIDERAÇÕES FINAIS}

Os dados demonstraram que a polifarmácia eleva o risco de prescrição de MPI, corroborando achados encontrados na literatura, obtidos em outros contextos. $\mathrm{O}$ fato de quase todos os MPI prescritos constarem na REMUME apontam para a necessidade de se incluir nos protocolos clínicos da Relação Nacional (RENAME) as restrições para uso desses medicamentos em idosos constantes no CBMPI.

A polifarmácia mostrou-se um fator frequente na APS, apontando a importância do acompanhamento do idoso pelo farmacêutico e pela equipe multiprofissional, a fim de garantir a conciliação medicamentosa e a identificação de possíveis iatrogenias.

Os resultados desta pesquisa evidenciam a prevalência da prescrição de MPI na Atenção Primária, com base no CBMPI, que se mostrou efetivo para identificação de MPIs. De fato, o Consenso demonstra ser um instrumento efetivo para auxiliar na orientação da melhor escolha terapêutica e redução da prescrição potencialmente inadequadas para idosos na prática clínica. O conhecimento dos critérios do CBMII pelas equipes multiprofissionais da APS auxilia na identificação de MPIs e realização dos encaminhamentos cabíveis para uma terapêutica segura.

Entende-se a importância da utilização dos critérios do CBMII como fonte de orientação na elaboração de protocolos clínicos específicos à terapêutica do idosos, como também atualização do programa de Assistência Farmacêutica para incremento da disponibilização de medicamentos na atenção primária (REMUME) que contemplem alternativas mais seguras de medicamentos para uso em idosos.

O fato de haver na REMUME-SP alternativas para mais da metade dos MPI prescritos mostra que não basta disponibilizá-las; é também necessário o planejamento e a implementação de iniciativas que conscientizem os profissionais sobre a prescrição de alternativas consideradas mais seguras para idosos, muitas das quais já estão disponíveis na REMUME, incluindo e destacando a importância das não farmacológicas, ainda que o uso das alternativas dependa de avaliação individualizada do idoso e das condições clínicas a serem tratadas. 


\section{7 - REFERÊNCIAS}

ALMEIDA, N. A. et al. Prevalence of and factors associated with polypharmacy among elderly persons resident in the community. Revista Brasileira de Geriatria e Gerontologia, v. 20, n. 1, p. 138-148, 2017.

ALMEIDA, N. A. et al. Factors associated with the use of potentially inappropriate medication by older adults in primary health care: An analysis comparing AGS Beers, EU(7)-PIM List, and Brazilian Consensus PIM criteria. Research in Social and Administrative Pharmacy, v. 15, n. 4, p. 370-377, 2019.

ALOMAR, M. J. Factors affecting the development of adverse drug reactions. Saudi pharmaceutical journal: SPJ: the official publication of the Saudi Pharmaceutical Society, v. 22, n. 2, p. 83-94, 2014. Disponível em: https://www.ncbi.nlm.nih.gov/pubmed/24648818. Acesso em: 10 Dez. 2018.

ALVES, L. C.; LEITE, I. D. C.; MACHADO, C. J. Conceituando e mensurando a incapacidade funcional da população idosa: uma revisão de literatura. Ciencia e Saúde Coletiva, v. 13, n. 4, p. 1199-1207, 2008.

ÁLVARES, J. et al. Acesso aos medicamentos pelos usuários da atenção primária no Sistema Único de Saúde. Revista de Saúde Pública, v. 51, supl. 2, 20s, 2017.

AMERICAN GERIATRICS SOCIETY (AGS) 2019 Updated AGS Beers Criteria for Potentially Inappropriate Medication Use in Older Adults. Journal of the American Geriatrics Society, v. 67, n. 4, p. 674-694, abr. 2019.

ARAUJO, L. U. et al. Segurança do paciente e polimedicação na Atenção Primária à Saúde: pesquisa transversal em pacientes com doenças crônicas. Revista Latino-Americana de Enfermagem, Ribeirão Preto , v. 27, e3217, 2019.

ASSATO, C. P.; BORJA-OLIVEIRA, C. R. Psicofármacos potencialmente inapropriados para idosos. Estudos Interdisciplinares sobre o Envelhecimento, v. 20, n. 3, p. 687-701, 2015.

BACHA, M. L.; PEREZ, G.; VIANNA, N. W. H. Terceira idade: uma escala para medir atitudes em relação a lazer. In: Anais ENANPAD, 30, 2006, Salvador: ANPAD, 2006.

BALDONI, A.O., PEREIRA, R.R.L. Estudo de utilização de medicamentos em idosos atendidos pelo Sistema Único de Saúde (SUS) [dissertação]. São Paulo (SP): Universidade de São Paulo; 2010. 43 p.

BARROS, M.B.A. et al. Tendências das desigualdades sociais e demográficas na prevalência de doenças crônicas no Brasil, PNAD: 2003-2008. Ciência e saúde coletiva, v. 16, n. 9, p. 3755-3768, 2011.

BITTENCOURT, S. C.; CAPONI, S.; MALUF, S. Farmacologia no século XX: A ciência dos medicamentos a partir da análise do livro de Goodman e Gilman. História, Ciências, Saúde - Manguinhos, v. 20, n. 2, p. 499$519,2013$.

BRASIL. Ministério da Saúde. Portaria no 2.528 de 19 de outubro de 2006. Aprova a Política Nacional de Saúde da Pessoa Idosa.

BRASIL. Estatuto do Idoso. 5. ed., revista e ampliada Lei $\mathbf{n}^{\mathbf{0}} \mathbf{1 0 . 7 4 1}$, de $\mathbf{1}^{\mathbf{0}}$ de outubro de 2003 (Estatuto do Idoso), e legislação correlata. Centro de Documentação e Informação Edições Câmara Brasília,| 2016.

BRASIL. Ministério do Orçamento e Gestão. Instituto Brasileiro de Geografia e Estatística. Pesquisa nacional por amostra de domicílios 2008 - Um Panorama da Saúde no Brasil - Acesso e Utilização dos Serviços, Condições de Saúde e Fatores de Risco e Proteção à Saúde. Rio de Janeiro: IBGE; 2010.

BRASIL. Ministério da Saúde. Decreto no. 7508, de 28 de junho de 2011. Regulamenta o a Lei no 8.080, de 19 de setembro de 1990, para dispor sobre a organização do Sistema Único de Saúde - SUS, planejamento da saúde, a assistência à saúde e a articulação interfederativa, e dá outras providências. 
BRASIL. Ministério da Saúde. Secretaria de Atenção à Saúde. Departamento de Atenção Básica. Política nacional de práticas integrativas e complementares no SUS: atitude de ampliação de acesso / Ministério da Saúde. Secretaria de Atenção à Saúde. Departamento de Atenção Básica. - 2. ed. - Brasília: Ministério da Saúde, 2015.

BRITO, F. Transição demográfica e desigualdades sociais no Brasil. Revista Brasileira de Estudos de População, v. 25, n. 1, p. 5-26, 2008.

CAMPOS, A. C. V.; GONÇALVES, L. H. T. Perfil demográfico do envelhecimento nos municípios do estado do Pará, Brasil. Revista Brasileira de Enfermagem, Brasília, v. 71, p. 591-598, 2018.

CASSONI, T.C.J. et al. Uso de medicamentos potencialmente inapropriados por idosos do Município de São Paulo, Brasil: Estudo SABE. Cadernos de Saúde Pública, v. 30, n. 8, p. 1708-1720, 2014.

CARVALHO, M.F.C. et al. Polifarmácia entre idosos do Município de São Paulo - Estudo SABE. Rev. bras. epidemiol., São Paulo, v. 15, n. 4, p. 817-827, Dec., 2012.

CHAIMOWICZ, F. Epidemiologia e o Envelhecimento no Brasil. In: FREITAS, E.V., PY, L., CANÇADO, F.A.X., DOLL, J., GORZONI, M.L. Tratado de Geriatria e Gerontologia. 2. ed. Rio de Janeiro: Guanabara Koogan, 2006.

CHAIMOWICZ, F. Saúde do Idoso. NESCON/UFMG - Curso de Especialização em Atenção Básica em Saúde da Família . 2.ed. Belo Horizonte: Nescon/UFMG, 2013. 179p.

CIOSAK, S. I. et al. Senescência e senilidade: novo paradigma na atenção básica de saúde. Revista da Escola de Enfermagem da USP, v. 45, n. spe2, p. 1763-1768, 2011.

FONSECA, J.E.; CARMO, T.A. O idoso e os medicamentos. Saúde em Revista, v. 2, n. 4, p. 35-41, 2000.

GALlAGHER, P. et al. STOPP (Screening Tool of Older Person's Prescriptions) and START (Screening Tool to Alert doctors to Right Treatment). Consensus validation. International Journal of Clinical Pharmacology and Therapeutics, v. 46, n. 2, p. 72-83, 2008.

GALLAGHER, P.; BARRY, P.; O’MAHONY, D. Inappropriate prescribing in the elderly. Journal of Clinical Pharmacy and Therapeutics, v. 32, n. 2, p. 113-121, abr. 2007.

GARSKE, C.C.D. et al. Medicamentos potencialmente inapropriados para idosos dispensados por uma farmácia básica do sul do Brasil. Revista Interdisciplinar de Promoção da Saúde, v. 1, n. 2, p. 31-42, 2018.

GOLDBAUM, M. et al. Utilização de serviços de saúde em áreas cobertas pelo programa de saúde da família (Qualis) no Município de São Paulo. Revista de Saúde Pública, v. 39, n. 1, p. 90-9, 2005.

GILMAN, ALFRED GOODMAN et al. (Ed.). Goodman and Gilman's: the pharmacological basis of therapeutics. 8.ed. New York: Pergamon Press. 1990.

GORZONI, M. L.; FABBRI, R. M. A.; PIRES, S. L. Critérios de beers-fick e medicamentos genéricos no Brasil. Revista da Associacão Médica Brasileira, v. 54, n. 4, p. 353-356, 2008.

GUTHRIE, B. Adapting clinical guidelines to take account of multimorbidity. British Medical Journal, v. 345, p. e6341, out. 2012.

GURWITZ, J. H. et al. Incidence and preventability of adverse drug events among older persons in the ambulatory setting. Journal of the American Medical Association, Chicago, v. 289, n. 9, p. 1107-16, 2003. Disponível em: https:// www.ncbi.nlm.nih.gov/pubmed/12622580. Acesso em: 12 Dez. 2018

HANLON, J.T., SEMLA, T.P., SCHMADER, K.E. Alternative Medications for Medications in the Use of HighRisk Medications in the Elderly and Potentially Harmful Drug-Disease Interactions in the Elderly Quality Measures. Journal of the American Geriatrics Society, v. 63, n. 12, p. e8-e18, 2015. 
HOLT, S.; SCHMIEDL, S.; THÜRMANN, P.A. Potentially Inappropriate Medications in the Elderly: The PRISCUS List. Deutsches Ärzteblatt International, v. 107, n. 31-32, p. 543-551, aug. 2010.

HUNT, L.M.; KREINER, M.; BRODY, H. The changing face of chronic illness management in primary care: a qualitative study of underlying influences and unintended outcomes. Annals of Family Medicine, v. 10, p. 45260, set. - out. 2012.

INOUYE, S. et al. Geriatric Syndromes: Clinical, Research and Policy Implications of a Core Geriatric Concept in older adults related to primary and secondary prevention. Journal of the American Geriatrics Society, v. 55, n. 5, p. 780-791, 2007.

LAROCHE, M.L.; CHARMES, J.P.; MERLE, L. Potentially inappropriate medications in the elderly: a French consensus panel list. European Journal of Clinical Pharmacology, v. 63, n. 8, p. 725-31, ago. 2007.

LOPES, L.M. et al. Use of potentially inappropriate medications by the elderly at home. Ciência e Saúde Coletiva, v. 21, n. 11, p. 3429-38, 2016.

LUTZ, B. H.; MIRANDA, V. I.A.; BERTOLDI, A. D. Inadequação do uso de medicamentos entre idosos em Pelotas, RS. Revista de Saúde Pública, v. 51, 52, 2017.

MCLEOD, P. J. et al. Defining inappropriate practices in prescribing for elderly people: a national consensus panel. Canadian Medical Association Journal, v. 156, n. 3, p. 385-91, fev. 1997.

MAGALHAES, M. S.; SANTOS, F. S.; REIS, ADRIANO, M. M. Fatores associados ao uso de medicamentos potencialmente inapropriados para idosos na alta hospitalar. Einstein (São Paulo), São Paulo, v. 18, eAO4877, 2020.

MANN, E. et al. Potentially inappropriate medication in geriatric patients: the Austrian consensus panel list. Wiener Klinische Wochenschrift, v. 124, n. 5-6, p. 160-9, mar. 2012.

MANSO, M.E.G.; BIFFI, E.C.A.; GERARDI, T.J. Prescrição inadequada de medicamentos a idosos portadores de doenças crônicas em um plano de saúde no município de São Paulo, Brasil.Rev Bras Geriatr Gerontol, v. 18, n. 1, p. 151-64, 2015.

MANSO, M.E.G.; BIFFI, E.C.A. Manual da LEPE Liga de Estudos do Processo do Envelhecimento. São Paulo: Martinari; 2014.

MELO, L. A.; LIMA, K.C. Prevalência e fatores associados a multimorbidades em idosos brasileiros. Ciência e Saúde Coletiva, dez, 2018. Disponível em http://www.cienciaesaudecoletiva.com.br/artigos/prevalencia-efatores-associados-a-multimorbidades-em-idosos-brasileiros/17063?id=17063

MORAES, E.N.; MARINO, M.C.A.; SANTOS, R.R. Principais síndromes geriátricas. Rev Med Minas Gerais; v. 20 , n. 1 , p. $54-66,2010$.

MORAES EN. Atenção à saúde do Idoso: Aspectos Conceituais. Brasília: Organização Pan-Americana da Saúde; 2012.

MARIN, M.J.S. et al. Use of medicines by the elderly in a Family Health Program unit in Brazil. Cad Saúde Pública, v. 24, n. 7, p. 1545-55, 2008.

MARIN N, et al. Seleção de medicamentos. In: Marin N, et al. Assistência farmacêutica para gerentes municipais. Rio de Janeiro: Organização Pan-Americana de Saúde/Organização Mundial da Saúde; 2003, p 13354.

MARTINS, G.A. et al. Uso de medicamentos potencialmente inadequados entre idosos do Município de Viçosa, Minas Gerais, Brasil: um inquérito de base populacional. Cad Saúde Pública, v. 31, n. 11, p. 2401-12, 2015.

MIRANDA, G. M. D.; MENDES, A. C. G.; SILVA, A. L. A. O envelhecimento populacional brasileiro: desafios e consequências sociais atuais e futuras. Revista Brasileira de Geriatria e Gerontologia, v. 19, n. 3, p. 507-519, Jun 2016. 
MOSCA, C.; CORREIA, P. O medicamento no doente idoso. Acta Farmacêutica Portuguesa, v. 1, n. 2, p. 7581, 2012.

MORIARTY, F. et al. Trends and interaction of polypharmacy and potentially inappropriate prescribing in primary care over 15 years in Ireland: a repeated cross-sectional study. BMJ Open, v. 5, p. 008656, set. 2015.

MOTTER, F.R., HILMER, S.N., PANIZ, V.M.V. (2019). Pain and Inflammation Management in Older Adults: A Brazilian Consensus of Potentially Inappropriate Medication and Their Alternative Therapies Front Pharmacology. Frontiers in Pharmacology, v. 10, p. 1408, 2019.

NASSUR, B.A. ET AL. Avaliação dos medicamentos inapropriados utilizados por idosos admitidos em hospital geral filantrópico. Revista Brasileira de Clínica Médica, v. 8, n. 3, p. 208-11, 2010.

NÓBREGA, O. DE T.; KARNIKOWSKI, M. G. DE O. A terapia medicamentosa no idoso: cuidados na medicação. Ciência \& Saúde Coletiva, v. 10, n. 2, p. 309-313, 2005.

OLIVEIRA, H. S. B.; CORRADI, M. L. G. Aspectos farmacológicos do idoso: uma revisão integrativa de literatura. Revista de Medicina (São Paulo), v. 97, n. 2, p. 165-76, mar-abr, 2018.

OLIVEIRA, M.G. et al. Brazilian consensus of potentially inappropriate medication for elderly people. Geriatrics Gerontology Aging, v. 10, n. 4, p. 168-81, 2016.

OLIVEIRA M.V.P.; BUARQUE, D.C. Polifarmácia e medicamentos potencialmente inapropriados em idosos admitidos em um hospital terciário. Maceió. Geriatrics, Gerontology And Aging, v. 12, n. 1, p. 38-42, 2018.

OLIVEIRA, R.E.M., NASCIMENTO, M.M.G., PEREIRA, M.L. Uso de medicamentos por idosos de uma unidade de atenção primária à saúde. Revista Brasileira de Farmácia Hospitalar e Serviços de Saúde, v. 7, n. 3, p. 30-34, 2016.

OLIVEIRA, M.A., BERMUDEZ, J.A.Z.; OSORIO-DE-CASTRO, C.G.S. Assistência farmacêutica e acesso a medicamentos. Rio de Janeiro: Editora Fiocruz; 2007. 112 p.

O'MAHONY, D. et al. STOPP/START criteria for potentially inappropriate prescribing in older people: version 2. Age Ageing, v. 44, n. 2, p. 213-8, 2015.

ORGANIZAÇÃO MUNDIAL DA SAÚDE (WHO). Envelhecimento ativo: uma política de saúde. Brasília, DF: OPAS; 2005.

ORGANIZAÇÃO MUNDIAL DA SAÚDE (WHO). Resumo Relatório Mundial de Envelhecimento e Saúde. 2015, p. 3-25.

ORGANIZACIÓN MUNDIAL DE LA SALUD (OMS). Selección de medicamentos esenciales. Perspectivas Políticas sobre Medicamentos de la OMS. Genebra: OMS; 2002.

PAULA JÚNIOR, J. D. P. et al. Prática de polifarmácia por idosos cadastrados em unidade de atenção primária. Investigação, Franca, v. 13, p. 15-18, 2013.

GORZONI, M. L ; PASSARELLI, M.C.G. Farmacologia e terapêutica na velhice. In: FREITAS, E.V., PY, L., CANÇADO, F.A.X., DOLL, J., GORZONI, M.L. Tratado de Geriatria e Gerontologia. 2.ed. Rio de Janeiro: Guanabara Koogan, 2006.

PINTO, M. C. X.; FERRÉ, F.; PINHEIRO, M. L. P. Potentially inappropriate medication use in a city of Southeast Brazil. Brazilian Journal of Pharmaceutical Sciences, v. 48, n. 1, p. 79-86, 2012.

ROSA, A. S. K. C. et al. Identificação de prescrição inapropriada em ambulatório de Geriatria utilizando os Critérios Stopp e Start. Revista Brasileira de Geriatria e Gerontologia, v.19, n. 5, p. 871-879, 2016.

ROSA,W.A.G; LABATE, R.C. Programa Saúde da Família: a construção de um novo modelo de assistência. Rev Latino-Am Enferm, v. 13, n. 6, p. 1027-1034, 2005. 
REIS, S.; CARDOSO, S. Multimorbilidade em cuidados de saúde primários: o que há de novo? Revista Portuguesa de Medicina Geral e Familiar, v. 31, n. 3, p. 230-232, jun. 2015.

RENOM-GUITERAS, A., MEYER, G., THÜRMANN, P. A. The EU(7)-PIM list: a list of potentially inappropriate medications for older people consented by experts from seven European countries. Eur J Clin Pharmacol, v. 71, n. 7, p. 861-875, 2015.

ROZENFELD, S.; FONSECA M.J.M.; ACURCIO F. A. Drug utilization and polypharmacya mong the elderly: a survey in Rio de Janeiro City, Brazil. Rev Panam Salud Publica/Pan Am J Public Health, v. 23, n. 1, p. 3443, 2008.

ROZENFELD, S. Prevalência, fatores associados e mau uso de medicamentos entre os idosos: uma revisão. Cad Saúde Pública, v. 19, n. 3, p. 717-724, 2003.

RIPSA, Rede Intergerencial de Informações da Saúde. Indicadores básicos de saúde no Brasil, Brasília, OPAS, 2012. Disponível em: http://fichas.ripsa.org.br/2012/. Acesso em: 13 mar.2019.

SANTOS, A. N. M., NOGUEIRA, D. R. C., BORJA-OLIVEIRA, C. R. Automedicação entre participantes de uma Universidade Aberta à Terceira Idade e fatores associados. Revista Brasileira de Geriatria e Gerontologia, v. 21, n. 4, p. 419-427, 2018.

SANTOS, A. N. M., NOGUEIRA, D. R. C., GUTIERREZ, B. A. O., CHUBACI R. Y. S., BORJA-OLIVEIRA, C. R. (2020). Doenças cardiometabólicas e envelhecimento ativo - a polifarmácia no controle. Rev. Bras. Enferm., Brasília, v. 73, n. 2, e20180324, 2020.

SÃO PAULO (Cidade). Secretaria Municipal de Desenvolvimento Urbano. Informe Urbano n.o 3: Cresce número de idosos na cidade de São Paulo. Novembro, 2011.

SÃO PAULO (CIDADE). Secretaria Municipal de Desenvolvimento Urbano. Informe Urbano n.o 37: Retrato da pessoa idosa na cidade de São Paulo. Março, 2019.

SEADE - http://produtos.seade.gov.br/produtos/projpop/index.php Acesso e processamento de dados em 30 nov/ 2019

SINNOTT, C. et al. GPs' perspectives on the management of patients with multimorbidity: systematic review and synthesis of qualitative research. BMJ Open, vol. 3, n. 9, p. e003610, 2013.

SILVA, E.A., MACEDO, L.C. Polifarmácia em idosos. Saúde e Pesquisa, v. 6, n. 3, set./dez, 2013.

SÖNNICHSEN, A. et al. Polypharmacy in chronic diseases-Reduction of Inappropriate Medication and Adverse drug events in older populations by electronic Decision Support (PRIMA-eDS): study protocol for a randomized controlled trial. Trials, v. 17, n. 1, p. 57, 2016.

SILVA, R.; SCHMIDT, O.F.; SILVA, S. Polifarmácia em geriatria. Rev AMRIGS, v. 56, n. 2, p.164-74, 2012. Disponível em: http:// www.amrigs.org.br/revista/56-02/revis.pdf.

SILVA, P. A. B. et al. Sociodemographic and clinical profile of elderly persons accompanied by Family Health teams under the gender perspective/Perfil sociodemográfico e clínico de idosos acompanhados por equipes de Saúde da Família sob a perspectiva do gênero. Revista de Pesquisa: Cuidado é Fundamental Online, v. 10, n. 1, p. 97-105, 2018.

STOPA, S. R. et al. Acesso e uso de serviços de saúde pela população brasileira, Pesquisa Nacional de Saúde 2013. Revista de Saúde Pública, v. 51, n. 1, p. 1s-11s, 2017.

STEINMAN, M.A. et al. How to Use the American Geriatrics Society 2015 Beers Criteria-A Guide for Patients, Clinicians, Health Systems, and Payors. Journal of the American Geriatrics Society, v. 63, n. 12, p. e1-e7, 2015. 
STARNER, C.I. et al. Geriatrics. Pharmacotherapy - A Pathophysiologic Approach, 7th Edition, Chap. 8, 2009.

VERA, E.C.B.A. Terapia medicamentosa do idoso: fatores de influência [dissertação]. São Paulo: Pontifícia Universidade Católica, Programa de Estudos Pós-graduados em Gerontologia; 2017.

VIEIRA, F.S. Qualificação dos serviços farmacêuticos no Brasil: aspectos inconclusos da agenda do Sistema Único de Saúde. Rev Panam Salud Publica, v. 24, n. 2, p. 91-100, 2008.

WORLD HEALTH ORGANIZATION (WHO). The uses of epidemiology in the study of the elderly. Geneva, 1984. 
ANEXO 1 - Planilha de prescrição de medicamentos

Unidade de Saúde

Período de coleta dos dados: de a

\begin{tabular}{|c|c|c|c|c|c|c|c|c|}
\hline $\begin{array}{l}\mathrm{N}^{\circ} \mathrm{de} \\
\text { ordem }\end{array}$ & $\begin{array}{c}\text { Data } \\
\text { da } \\
\text { receita }\end{array}$ & $\begin{array}{c}\text { Idade } \\
\text { do } \\
\text { paciente }\end{array}$ & Sexc & Medicamento & $\begin{array}{c}\text { Dose } \\
(\mathrm{em} \\
\mathrm{mg})\end{array}$ & $\begin{array}{c}\mathrm{N}^{\mathrm{o}} \text { de } \\
\text { tomadas } \\
/ \mathrm{dia}\end{array}$ & $\begin{array}{l}\text { Tempo de } \\
\text { duração do } \\
\text { tratamento }\end{array}$ & $\begin{array}{c}\text { Serviço que } \\
\text { prescreveu os } \\
\text { medicamentos } \\
\text { (UBS, PSF, } \\
\text { Hospital, } \\
\text { AMA, AME, } \\
\text { convênio). }\end{array}$ \\
\hline & & & & & & & & \\
\hline & & & & & & & & \\
\hline & & & & & & & & \\
\hline & & & & & & & & \\
\hline & & & & & & & & \\
\hline & & & & & & & & \\
\hline & & & & & & & & \\
\hline & & & & & & & & \\
\hline & & & & & & & & \\
\hline & & & & & & & & \\
\hline & & & & & & & & \\
\hline & & & & & & & & \\
\hline
\end{tabular}


ANEXO 2 - Quadro 1 do CBMPI.

Quadro 1 Descrição dos critérios para medicamentos que devem ser evitados em idosos, independentes de condição clínica.

\begin{tabular}{|c|c|c|c|}
\hline Número & Critério & Racional & Exceção \\
\hline \multicolumn{4}{|c|}{ Sistema Nervoso Central e Medicamentos Psicotrópicos } \\
\hline 1 & $\begin{array}{l}\text { Antiparkinsonianos com forte ação } \\
\text { anticolinérgica (biperideno e triexifenidil) } \\
\text { para tratar os efeitos extrapiramidais de } \\
\text { medicamentos neurolépticos. }\end{array}$ & Risco de toxicidade anticolinérgica. & - \\
\hline 2 & $\begin{array}{l}\text { Anti-histamínicos de primeira geração } \\
\text { (Bronfeniramina, Carbinoxamina, } \\
\text { Ciproeptadina, Clemastina, Clorfeniramina, } \\
\text { Dexclorfeniramina, Difenidramina, } \\
\text { Dimenidrinato, Doxilamina, Hidroxizina, } \\
\text { Meclizina, Prometazina, Triprolidina). }\end{array}$ & $\begin{array}{c}\text { Risco de sedação e efeitos } \\
\text { anticolinérgicos (confusão, boca } \\
\text { seca, constipação, entre outros). Há } \\
\text { o desenvolvimento de tolerância, } \\
\text { quando utilizados como hipnótico. }\end{array}$ & $\begin{array}{l}\text { O uso de Difenidramina, em } \\
\text { situações como reação alérgica } \\
\text { grave, pode ser apropriado. }\end{array}$ \\
\hline 3 & $\begin{array}{c}\text { Antipsicóticos de primeira geração } \\
\text { (Clorpromazina, Flufenazina, Haloperidol, } \\
\text { Levomepromazina, Penfluridol, Periciazina, } \\
\text { Pimozida, Pipotiazina, Sulpirida, Tioridazina, } \\
\text { Trifluoperazina, Zuclopentixol) e de } \\
\text { segunda geração (Amissulprida, Aripiprazol, } \\
\text { Clozapina, Olanzapina, Paliperidona, } \\
\text { Quetiapina, Risperidona, Ziprasidona) para } \\
\text { problemas comportamentais da demência. }\end{array}$ & $\begin{array}{l}\text { Aumento do risco de acidente vascular } \\
\text { cerebral (AVC) e mortalidade. }\end{array}$ & $\begin{array}{l}\text { O uso deve ser restrito aos } \\
\text { casos nos quais estratégias não } \\
\text { farmacológicas tenham falhado } \\
\text { ou quando o paciente representa } \\
\text { ameaça a si ou a outros. }\end{array}$ \\
\hline 4 & Barbitúricos (Fenobarbital, Tiopental). & $\begin{array}{l}\text { Alta proporção de dependência física, } \\
\text { tolerância na indução do sono e risco } \\
\text { de overdose em doses baixas. }\end{array}$ & - \\
\hline 5 & $\begin{array}{l}\text { Benzodiazepinicos (Alprazolam, } \\
\text { Bromazepam, Clobazam, Clonazepam, } \\
\text { Clordiazepóxido, Cloxazolam, Diazepam, } \\
\text { Estazolam, Flunitrazepam, Flurazepam, } \\
\text { Lorazepam, Midazolam, Nitrazepam). }\end{array}$ & $\begin{array}{l}\text { Em geral, os benzodiazepínicos } \\
\text { aumentam o risco de } \\
\text { comprometimento cognitivo, } \\
\text { delirium, quedas, fraturas e } \\
\text { acidentes automobilísticos. Evitar } \\
\text { todos os benzodiazepinicos para } \\
\text { tratar insônia, agitação ou delirium. }\end{array}$ & $\begin{array}{l}\text { Podem ser apropriados para tratar } \\
\text { crises convulsivas, distúrbios } \\
\text { do sono REM, sindrome de } \\
\text { abstinência a benzodiazepínicos } \\
\text { e etanol, transtorno de ansiedade } \\
\text { generalizada grave, em anestesia } \\
\text { perioperatória e cuidados paliativos. }\end{array}$ \\
\hline
\end{tabular}




\section{ANEXO 2 - Quadro 1 do CBMPI (continuação).}

\begin{tabular}{|c|c|c|c|}
\hline Número & Critério & Racional & Exceção \\
\hline 6 & $\begin{array}{l}\text { Mesilato de codergocrina para } \\
\text { tratamento de demência. }\end{array}$ & Ausência de eficácia. & - \\
\hline 7 & $\begin{array}{l}\text { Uso prolongado de neurolépticos } \\
\text { como hipnóticos. }\end{array}$ & $\begin{array}{l}\text { Risco de confusão, hipotensão, } \\
\text { efeitos extrapiramidais e quedas. }\end{array}$ & - \\
\hline 8 & $\begin{array}{l}\text { Evitar uso crônico (> } 90 \text { dias) de hipnóticos } \\
\text { não benzodiazepínicos (Zolpidem). }\end{array}$ & $\begin{array}{c}\text { Efeitos adversos similares aos } \\
\text { benzodiazepínicos (por exemplo: } \\
\text { delirium, quedas, fraturas). Pequena } \\
\text { melhora na latência e duração do sono. }\end{array}$ & - \\
\hline 9 & $\begin{array}{l}\text { Antidepressivos tricíclicos terciários } \\
\text { (Amitriptilina, Imipramina, } \\
\text { Nortriptilina,Clomipramina, Maprotilina) } \\
\text { sozinhos ou em combinação. }\end{array}$ & $\begin{array}{l}\text { Altamente anticolinérgicos, sedativos } \\
\text { e causam hipotensão ortostática. }\end{array}$ & $\begin{array}{l}\text { Podem ser apropriados para tratamento } \\
\text { da dor e/ou depressão grave. Pode ser } \\
\text { apropriado o uso da Nortriptilina para } \\
\text { tratamento da depressão associada à } \\
\text { doença de Parkinson em idosos jovens. }\end{array}$ \\
\hline 10 & Tioridazina. & $\begin{array}{l}\text { Altamente anticolinérgico e risco de } \\
\text { prolongamento do intervalo QT. }\end{array}$ & - \\
\hline \multicolumn{4}{|c|}{ Sistema Cardiovascular } \\
\hline 11 & $\begin{array}{l}\text { Bloqueadores Alfa-1 para tratamento da } \\
\text { hipertensão (Doxazosina, Prazosina, Terazosina). }\end{array}$ & $\begin{array}{l}\text { Uso associado ao alto risco de } \\
\text { hipotensão ortostática. Não } \\
\text { recomendados para tratamento de } \\
\text { rotina da hipertensão. Há alternativas } \\
\text { com melhor relação risco-benefício. }\end{array}$ & - \\
\hline 12 & $\begin{array}{l}\text { Alfa agonistas de ação central para } \\
\text { tratamento de rotina da hipertensão [Clonidina, } \\
\text { Metildopa, Reserpina (>0,1 mg/dia)]. }\end{array}$ & $\begin{array}{l}\text { Alto risco de efeitos adversos ao } \\
\text { Sistema Nervoso Central (SNC). } \\
\text { Podem causar bradicardia e } \\
\text { hipotensão ortostática. }\end{array}$ & - \\
\hline 13 & $\begin{array}{l}\text { Medicamentos antiarritmicos classes } \\
\text { la, Ic, III (Amiodarona, Propafenona, } \\
\text { Quinidina, Sotalol). }\end{array}$ & $\begin{array}{l}\text { Dados sugerem que o controle da } \\
\text { frequência cardiaca proporciona melhor } \\
\text { perfil risco-beneficio do que o controle } \\
\text { do ritmo em idosos. A Amiodarona } \\
\text { está associada a doenças da tireóide, } \\
\text { distúrbios pulmonares e prolongamento } \\
\text { do intervalo QT. }\end{array}$ & - \\
\hline 14 & Aspirina em dose $>150 \mathrm{mg} / \mathrm{dia}$. & $\begin{array}{l}\text { Aumento do risco de hemorragia } \\
\text { digestiva, sem evidência de } \\
\text { aumento da eficácia. }\end{array}$ & - \\
\hline 15 & $\begin{array}{l}\text { Aspirina para tratar tonturas não claramente } \\
\text { atribuiveis à doença cerebrovascular. }\end{array}$ & Não está indicada. & - \\
\hline 16 & Digoxina > 0,125 mg/dia. & $\begin{array}{l}\text { A diminuição do clearance renal com } \\
\text { o envelhecimento aumenta o risco de } \\
\text { intoxicação digitálica. Além disso, na } \\
\text { insuficiência cardíaca, as doses mais } \\
\text { altas elevam o risco de toxicidade e } \\
\text { não oferecem maiores benefícios. }\end{array}$ & - \\
\hline 17 & $\begin{array}{l}\text { Dipiridamol (comprimido de liberação } \\
\text { imediata) como monoterapia para prevenção } \\
\text { secundária de eventos cardiovasculares. }\end{array}$ & $\begin{array}{c}\text { Sem evidência de eficácia como } \\
\text { monoterapia para prevenção secundária } \\
\text { de eventos cardiovasculares. Pode } \\
\text { causar hipotensão ortostática Há } \\
\text { alternativas mais eficazes disponíveis. }\end{array}$ & - \\
\hline 18 & $\begin{array}{l}\text { Diuréticos de alça (Bumetanida, Furosemida, } \\
\text { Piretanida) para edema de tomozelo, na ausência } \\
\text { de sinais clínicos de insuficiência cardíaca }\end{array}$ & $\begin{array}{c}\text { Não há evidência da eficácia. Meias } \\
\text { de compressão geralmente são } \\
\text { mais apropriadas. }\end{array}$ & - \\
\hline 19 & $\begin{array}{c}\text { Diuréticos de alça (Bumetanida, Furosemida, } \\
\text { Piretanida) como monoterapia de primeira } \\
\text { linha para hipertensão. }\end{array}$ & $\begin{array}{l}\text { Há alternativas mais } \\
\text { seguras e eficazes. }\end{array}$ & - \\
\hline 20 & Nifedipino, cápsula de liberação imediata. & $\begin{array}{l}\text { Potencial para hipotensão. Risco de } \\
\text { isquemia miocárdica. }\end{array}$ & - \\
\hline
\end{tabular}


ANEXO 2 - Quadro 1 do CBMPI (continuação).

\begin{tabular}{|c|c|c|c|}
\hline Número & Critério & Racional & Exceção \\
\hline 21 & $\begin{array}{l}\text { Espironolactona }>25 \mathrm{mg} / \mathrm{dia} \text { (pacientes com } \\
\text { insuficiência cardiaca ou } \mathrm{CrCl}<30 \mathrm{~mL} / \mathrm{min} \text { ). }\end{array}$ & $\begin{array}{l}\text { Risco de hipercalemia em pacientes com } \\
\text { insuficiência cardiaca, especialmente com } \\
\text { uso concomitante de anti-inflamatórios } \\
\text { não esteroides, Inibidores da Enzima } \\
\text { Conversora de Angiotensina (IECA) ou } \\
\text { bloqueadores do receptor da angiotensina }\end{array}$ & - \\
\hline 22 & Ticlopidina. & $\begin{array}{l}\text { Há alternativas mais seguras e } \\
\text { eficazes disponiveis. }\end{array}$ & - \\
\hline \multicolumn{4}{|c|}{ Sistema Endocrino } \\
\hline 23 & $\begin{array}{l}\text { Estrógenos (com ou sem progesteronas). } \\
\text { Evitar formas orais e adesivos transdérmicos. }\end{array}$ & $\begin{array}{c}\text { Evidência de potencial carcinogênico } \\
\text { (mama e endométrio). Além disso, } \\
\text { ausência de efeito cardioprotetor e } \\
\text { de proteção cognitiva em idosas. }\end{array}$ & - \\
\hline 24 & Andrógenos. & $\begin{array}{c}\text { Potenciais para problemas cardíacos } \\
\text { e contraindicados para homens com } \\
\text { câncer de próstata. }\end{array}$ & $\begin{array}{l}\text { Evitar, a menos que estejam } \\
\text { indicados para hipogonadismo } \\
\text { moderado a grave. }\end{array}$ \\
\hline 25 & Clorpropamida. & $\begin{array}{l}\text { Meia-vida prolongada em idosos. } \\
\text { Pode causar hipoglicemia e } \\
\text { síndrome de secreção inapropriada } \\
\text { do hormônio antidiurético. }\end{array}$ & - \\
\hline 26 & Glibenclamida. & $\begin{array}{l}\text { Maior risco de hipoglicemia } \\
\text { prolongada grave em idosos. }\end{array}$ & - \\
\hline 27 & Hormônio do crescimento (Somatropina). & $\begin{array}{c}\text { Efeito sobre a composição corporal é } \\
\text { pequeno e está associado ao surgimento } \\
\text { de edema, artralgia, sindrome do túnel } \\
\text { do carpo, ginecomastia e glicose de } \\
\text { jejum alterada. }\end{array}$ & $\begin{array}{c}\text { Evitar, exceto em casos de reposição } \\
\text { hormonal, após remoção da } \\
\text { glândula pituitária. }\end{array}$ \\
\hline \multicolumn{4}{|c|}{ Sistema Gastrointestinal } \\
\hline 28 & $\begin{array}{l}\text { Antiespasmódicos gastrointestinais } \\
\text { (Hiosciamina, Escopolamina). }\end{array}$ & $\begin{array}{l}\text { Altamente anticolinérgicos. } \\
\text { Efetividade incerta. }\end{array}$ & $\begin{array}{l}\text { Evitar, exceto em cuidado paliativo de } \\
\text { curto prazo para reduzir secreções orais. }\end{array}$ \\
\hline 29 & $\begin{array}{l}\text { Loperamida ou Codeína para tratamento } \\
\text { de diarreia de causa desconhecida ou } \\
\text { gastroenterite infecciosa grave. }\end{array}$ & $\begin{array}{l}\text { Risco de diagnóstico tardio. Pode agravar } \\
\text { a constipação com diarreia espúria e } \\
\text { precipitar megacólon tóxico na doença } \\
\text { inflamatória do intestino e retardar a } \\
\text { recuperação da gastroenterite. Nos } \\
\text { casos de gastroenterite infecciosa } \\
\text { grave, existe o risco de exacerbação ou } \\
\text { prolongamento da infecção. }\end{array}$ & - \\
\hline 30 & Metoclopramida. & $\begin{array}{c}\text { Pode causar efeitos extrapiramidais } \\
\text { incluindo discinesia tardia. Risco pode } \\
\text { ser ainda maior em idosos mais frágeis. }\end{array}$ & $\begin{array}{l}\text { Evitar, exceto em casos de } \\
\text { gastroparesia. }\end{array}$ \\
\hline 31 & Óleo mineral (via oral). & $\begin{array}{c}\text { Potencial para aspiração e efeitos } \\
\text { adversos. Alternativas mais } \\
\text { seguras disponiveis. }\end{array}$ & - \\
\hline 32 & $\begin{array}{l}\text { Inibidores de bomba de prótons (Omeprazol, } \\
\text { Pantoprazol, Lanzoprazol, Rabeprazol, } \\
\text { Esomeprazol e Tenatoprazol), para úlcera } \\
\text { péptica na dosagem terapêutica integral por } \\
>8 \text { semanas. }\end{array}$ & $\begin{array}{l}\text { Potencial para desenvolvimento de } \\
\text { osteoporose/fratura, demência e } \\
\text { insuficiência renal com o uso prolongado. }\end{array}$ & $\begin{array}{l}\text { Descontinuação antes de oito semanas } \\
\text { de uso ou redução da dose para } \\
\text { tratamento, manutenção/profilático de } \\
\text { úlcera péptica, esofagite ou Doença do } \\
\text { Refluxo Gastroesofágico. }\end{array}$ \\
\hline \multicolumn{4}{|c|}{ Sistema Musculoesquelético } \\
\hline 33 & $\begin{array}{l}\text { Relaxantes musculares (Carisoprodol, } \\
\text { Ciclobenzaprina, Orfenadrina). }\end{array}$ & $\begin{array}{l}\text { A maioria dos relaxantes musculares } \\
\text { é mal tolerada por idosos devido } \\
\text { aos efeitos anticolinérgicos, como } \\
\text { sedação e consequente risco de } \\
\text { fratura. A efetividade em doses } \\
\text { toleradas por idosos é questionável. }\end{array}$ & - \\
\hline
\end{tabular}


ANEXO 2 - Quadro 1 do CBMPI (continuação).

\begin{tabular}{|c|c|c|c|}
\hline Número & Critério & Racional & Exceção \\
\hline 34 & $\begin{array}{l}\text { Uso prolongado de anti-inflamatórios não } \\
\text { esteroides (AINE) não seletivos da COX2 } \\
\text { (Aspirina > } 325 \mathrm{mg} / \mathrm{dia} \text {, Diclofenaco, Etodolaco, } \\
\text { Fenoprofeno, Ibuprofeno, Cetoprofeno, } \\
\text { Meloxicam, Naproxeno, Piroxicam). }\end{array}$ & $\begin{array}{c}\text { Aumentam o risco de hemorragia } \\
\text { gastrointestinal e úlcera péptica } \\
\text { em grupos de alto risco, incluindo } \\
\text { aqueles com idade }>75 \text { anos ou } \\
\text { que utilizam corticosteroides orais } \\
\text { ou parenterais, anticoagulantes ou } \\
\text { antiplaquetários. O uso de inibidores } \\
\text { da bomba de prótons reduz, mas } \\
\text { não elimina o risco. }\end{array}$ & $\begin{array}{l}\text { Evitar uso crônico, exceto quando } \\
\text { não houver outras alternativas e } \\
\text { for possivel associação com agente } \\
\text { gastroprotetor. }\end{array}$ \\
\hline 35 & Indometacina. & $\begin{array}{l}\text { Aumenta o risco de hemorragia } \\
\text { gastrointestinal e úlcera péptica em } \\
\text { grupos de alto risco. Entre os anti- } \\
\text { inflamatórios não esteroides (AINE), } \\
\text { a Indometacina é o agente que } \\
\text { causa mais efeitos adversos. }\end{array}$ & - \\
\hline 36 & Cetorolaco. & $\begin{array}{l}\text { Aumenta o risco de hemorragia } \\
\text { gastrointestinal e úlcera péptica em } \\
\text { grupos de alto risco, por pertencer } \\
\text { à classe dos anti-inflamatórios não } \\
\text { esteroides (AINE). }\end{array}$ & - \\
\hline 37 & $\begin{array}{l}\text { Uso prolongado (> } 3 \text { meses) de } \\
\text { corticosteroides sistêmicos (Betametasona, } \\
\text { Budesonida, Deflazacorte, Dexametasona, } \\
\text { Fludrocortisona, Hidrocortisona, } \\
\text { Metilprednisolona, Prednisolona, Prednisona) } \\
\text { como monoterapia para artrite reumatoide } \\
\text { ou osteoartrite. }\end{array}$ & Risco de efeitos adversos graves. & - \\
\hline 38 & $\begin{array}{l}\text { Uso prolongado de Colchicina para } \\
\text { tratamento de longo prazo da gota, se não } \\
\text { existir contraindicação ao alopurinol. }\end{array}$ & $\begin{array}{c}\text { O alopurinol é o medicamento } \\
\text { profilático de primeira escolha na gota. }\end{array}$ & - \\
\hline 39 & $\begin{array}{l}\text { Uso prolongado de opióides fortes (Alfentanila, } \\
\text { Fentanila, Hidromorfona, Metadona, Morfina, } \\
\text { Nalbufina, Oxicodona, Petidina, Remifentanila, } \\
\text { Sufentanila) como terapia de primeira linha } \\
\text { para dor leve/moderada. }\end{array}$ & Não segue a escala analgésica da OMS. & - \\
\hline 40 & Petidina (Dolantina/Meperidina). & $\begin{array}{l}\text { Não é um analgésico efetivo por } \\
\text { via oral, em doses normalmente } \\
\text { utilizadas. Pode causar } \\
\text { neurotoxicidade. Há alternativas } \\
\text { mais seguras disponíveis. }\end{array}$ & - \\
\hline \multicolumn{4}{|c|}{ Diversos } \\
\hline 41 & Nitrofurantoína. & $\begin{array}{l}\text { Potencial para toxicidade pulmonar. } \\
\text { Apresenta perda de eficácia em } \\
\text { pacientes com } \mathrm{ClCr}<60 \mathrm{~mL} / \mathrm{min} \\
\text { devido à concentração inadequada } \\
\text { do fármaco na urina. Há alternativas } \\
\text { mais seguras disponiveis. }\end{array}$ & - \\
\hline 42 & $\begin{array}{l}\text { Corticosteroides sistêmicos (Betametasona, } \\
\text { Deflazacorte, Dexametasona, Hidrocortisona, } \\
\text { Metilprednisolona, Prednisolona, Prednisona) } \\
\text { em vez de corticosteroides inalatórios, para } \\
\text { terapia de manutenção da Doença Pulmonar } \\
\text { Obstrutiva Crônica (DPOC) moderada a grave. }\end{array}$ & $\begin{array}{l}\text { Exposição desnecessária aos } \\
\text { efeitos adversos de longo prazo dos } \\
\text { corticosteroides sistêmicos. }\end{array}$ & - \\
\hline 43 & $\begin{array}{l}\text { Teofilina como monoterapia para a doença } \\
\text { pulmonar obstrutiva crônica. }\end{array}$ & $\begin{array}{c}\text { Existência de alternativa mais } \\
\text { segura e efetiva. Além disso, risco } \\
\text { de efeitos adversos devido ao indice } \\
\text { terapêutico estreito. }\end{array}$ & - \\
\hline
\end{tabular}




\title{
ANEXO 3 - Termo de consentimento livre e esclarecido
}

\author{
TERMO DE CONSENTIMENTO LIVRE E ESCLARECIDO \\ Projeto de pesquisa: Avaliação do uso de medicamentos em idosos de três Unidades de Saúde da Família \\ na zona leste do município de São Paulo
}

\author{
Prezado (a) Senhor (a), \\ Pedimos o favor de dedicar alguns minutos do seu tempo para ler este comunicado.
}

A Atenção Primária à Saúde (APS) Santa Marcelina procurando cumprir o propósito de oferecer uma Atenção Primária à Saúde de qualidade, quer saber quais são os medicamentos mais utilizados pelos indivíduos com 60 anos ou mais, qual a dose, a posologia, o tempo de tratamento indicado, desta forma, vem propor a presente pesquisa.

Serão convidados a participar desta pesquisa todos os indivíduos portando receitas médicas de indivíduos com 60 anos ou mais que estiverem procurando obter os medicamentos prescritos na farmácia das Unidades de Saúde, durante o período de realização da pesquisa.

Sua participação nesta pesquisa poderá ocorrer de duas maneiras. Se a receita tiver cópia, que deverá ficar arquivada na farmácia, o $\mathrm{Sr}$ (a) autorizando, vamos registrar em um banco de dados quais foram os medicamentos, doses, posologia e tempo de tratamento prescritos pelo seu médico. Caso o (a) senhor (a) não tenha cópia da receita, vamos transcrever de sua receita para uma planilha: nome dos medicamentos prescritos, dose e posologia indicada bem como o tempo de duração do tratamento, qual o tipo de serviço que deu origem à receita (UBS, AMA, AME, Hospital, etc....) . O (a) Sr (a) será solicitado a responder algumas questões como: idade e sexo do indivíduo que fará uso dos medicamentos.

Esclarecemos que sua participação é decorrente de sua livre decisão, após receber todas as informações que julgar necessárias. Você não será prejudicado de qualquer forma caso sua vontade seja de não colaborar. Os dados individuais não serão divulgados em nenhuma hipótese, mas os resultados da pesquisa poderão ajudar a melhorar a qualidade da Atenção Primária à Saúde oferecida à população.

Se quiser mais informações sobre a pesquisa, por favor, ligue para o Setor de Pesquisas da Coordenação da APS Santa Marcelina, 2056-62-62 e converse com Dra. Julie Silvia Martins ou Dra. Michelle Quevedo (Ramal 6252), ou então, fale pessoalmente com uma delas no Setor de Pesquisas da Coordenação da APS Santa Marcelina na Rua Fontoura Xavier, 1037 - Vila Carmosina - Itaquera.

Qualquer questão, dúvida, esclarecimento ou reclamação sobre aspectos éticos dessa pesquisa, favor entrar em contato com: Comitê de Ética em Pesquisas da Secretaria Municipal da Saúde de São Paulo - Rua General Jardim, 36 - 1. ${ }^{\circ}$ andar - CEP 01223-010 - São Paulo -Capital Telefone: 3397-2464 - FAX: 3397-2465 - e-mail: smscep@gmail.com

Caso concorde em participar da pesquisa, solicitamos que preencha os dados solicitados a seguir e assine, autorizando a utilização destas informações para fins de pesquisa.

Consentimento pós-informação: $\mathrm{Eu}$, .RG

n. ${ }^{\circ}$....................................... li e compreendi a natureza e finalidade desse estudo e voluntariamente, aceitei participar desta pesquisa. Afirmo ainda que recebi uma via deste termo para ficar em meu poder.

São Paulo, de de 2013.

Assinatura do participante 